\title{
Recognition of CD1d-restricted antigens by natural killer T cells
}

\author{
Jamie Rossjohn ${ }^{1}$, Daniel G. Pellicci ${ }^{2}$, Onisha Patel ${ }^{1}$, Laurent Gapin ${ }^{3}$, and Dale I. Godfrey ${ }^{2}$ \\ ${ }^{1}$ Department of Biochemistry and Molecular Biology, School of Biomedical Sciences, Monash \\ University, Clayton, Victoria 3800, Australia \\ ${ }^{2}$ Department of Microbiology \& Immunology, University of Melbourne, Parkville, Victoria 3010 , \\ Australia \\ ${ }^{3}$ Department of Immunology, University of Colorado School of Medicine, Denver, and National \\ Jewish Health, Denver, Colorado 80206, USA
}

\begin{abstract}
Natural killer T (NKT) cells are innate-like T cells that rapidly produce a variety of cytokines following T cell receptor (TCR) activation and can shape the immune response in many different settings. There are two main NKT cell subsets: type I NKT cells are typically characterized by the expression of a semi-invariant TCR, whereas the TCRs expressed by type II NKT cells are more diverse. This Review focuses on the defining features and emerging generalities regarding how NKT cells specifically recognize self, microbial and synthetic lipid-based antigens that are presented by CD1d. Such information is vitally important to better understand, and fully harness, the therapeutic potential of NKT cells.
\end{abstract}

$\mathrm{T}$ cells are usually viewed as being specific for peptide antigens that are presented on classical MHC molecules. However, many T cells actually respond to lipid-based antigens that are presented by the $\mathrm{CD} 1$ family of MHC-like molecules, which are typically expressed by professional antigen-presenting cells (APCs). The CD1 family is subdivided into at least three groups: group 1 comprises $\mathrm{CD} 1 \mathrm{a}, \mathrm{CD} 1 \mathrm{~b}$ and $\mathrm{CD} 1 \mathrm{c}$; group 2 comprises $\mathrm{CD} 1 \mathrm{~d}$; and group 3 comprises $C D 1 \mathrm{e}^{1,2}$. The most extensively studied type of lipid-reactive $\mathrm{T}$ cell is the CD1d-restricted natural killer T (NKT) cell $^{3}$ (FIG. 1a).

NKT cells are a specialized T cell subset that is functionally distinct from MHC-restricted T cells ${ }^{4}$. For example, NKT cells can rapidly produce very large amounts of cytokines including interferon- $\gamma(\mathrm{IFN} \gamma)$, interleukin-4 (IL-4), IL-10, IL-13, IL-17, IL-21 and tumour necrosis factor (TNF) - following stimulation, and they are able to either promote or suppress cell-mediated immunity without the need for clonal expansion ${ }^{5,6}$. Thus, NKT cells can enhance the immune response to a range of infectious organisms, and some types of cancer, but can also suppress autoimmune disease, allograft rejection and graft-versus-host disease $^{3}$. Consequently, NKT cells represent a potentially important immunotherapeutic target with widespread clinical potential ${ }^{7-9}$.

The interaction between the NKT cell antigen receptor - that is, the T cell receptor (TCR) expressed by NKT cells (referred to as the NKT TCR in this article) - and the antigenCD1d complex represents a central event leading to NKT cell activation ${ }^{10}$. Since 2006,

() 2012 Macmillan Publishers Limited. All rights reserved

Correspondence to: J.R. and D.I.G. jamie.rossjohn@monash.edu; godfrey@unimelb.edu.au.

Competing interests statement

The authors declare no competing financial interests. 
many studies on antigen recognition by NKT TCRs have helped us to begin to understand the factors that govern the antigenicity of a given ligand. Although CD1d is essentially monomorphic, it can bind to an array of lipid-based antigens, including synthetic, self and non-self antigens ${ }^{11-13}$. Uncovering the NKT cell stimulatory properties of these antigens, and the rules of engagement in the various NKT TCR-antigen-CD1d complexes, represents a key step in understanding NKT cell biology. This Review primarily focuses on how the various forms of type I NKT TCR function like 'pattern-recognition receptors' in engaging a variety of lipid-based antigens that exhibit diverse chemistries. We also highlight the contrasting 'snapshot' of type II NKT TCR-mediated antigen recognition, as well as the factors that govern the general principles of NKT cell-mediated antigen recognition and therapeutic implications.

\section{NKT cell subsets}

The $a \beta$ TCR is composed of an $a$-chain and a $\beta$-chain, with each chain being subdivided into a variable $(\mathrm{V})$ domain and a constant $(\mathrm{C})$ domain. In TCR $a$-chains, the $\mathrm{V}$ domains are encoded by $\mathrm{V}(T R A V)$ and joining (J; TRAJ) gene segments, whereas TCR $\beta$-chain $\mathrm{V}$ domains are encoded by $\mathrm{V}(T R B V)$, diversity $(\mathrm{D} ; T R B D)$ and $\mathrm{J}$ (TRBJ) gene segments. Within the $\mathrm{V}$ domains, three complementarity-determining regions (CDRs) in each chain collectively form the antigen-binding site of the TCR. The CDR1 and CDR2 loops are encoded within the V gene segments, whereas the CDR3 loop is encoded at the junction of the rearranged $\mathrm{V}$ and $\mathrm{J}$ gene segments (for TCRa) or V, D and J gene segments (for TCR $\beta$ ). The various permutations and combinations of $\mathrm{V}, \mathrm{D}$ and $\mathrm{J}$ gene segments endow the CDR3 loops with the greatest diversity, which is further enhanced by random non-templated alterations at the $\mathrm{V}(\mathrm{D}) \mathrm{J}$ gene junctional boundaries (FIG. 1b).

\section{Type I NKT cells}

There are two main subsets of NKT cells, termed type I and type II NKT cells (FIG. 1). Type I NKT cells typically express an 'invariant' TCR a-chain (Va24Ja 18 (TRAV10 TRAJ18) in humans and the orthologous chain Va14Ja18 (Trav11-Traj18) in mice), which is paired with a limited set of TCR $\beta$-chains (comprising V $\beta 11$ (TRBV25-1) in humans and V $\beta 8.2$ (Trbv13-2), V $\beta 7$ (Trbv1) or V $\beta 2$ (Trbv29) in mice $)^{4,14-16}$. There is a high level of sequence identity in the CDR3 $\alpha$ and CDR2 $\beta$ loops from human and mouse type I NKT $\mathrm{TCRs}^{16}$, which underpins the evolutionarily conserved reciprocal cross-species reactivity of these cells between mice and humans ${ }^{17-19}$. The importance of the CDR3a loop for NKT cell function is highlighted by the loss of most type I NKT cells in TCR Ja 18 gene-targeted mice $^{20}$, although studies on these mice may need to be revisited owing to a recent report that suggests that the diversity of the overall TCR repertoire is reduced in these mice ${ }^{21}$. As type I NKT cells typically express an invariant TCR a-chain, they are frequently referred to as 'invariant' NKT cells ${ }^{4}$. However, this is clearly a misnomer because NKT cells exhibit a high degree of natural variability in the CDR $3 \beta$ loop ${ }^{16,22,23}$. Thus, 'semi-invariant' is a more accurate, although still imperfect, description for type I NKT cells"

Another parameter that is typically used to define type I NKT cells is their ability to recognize a-galactosylceramide $(\mathrm{aGalCer})^{4}$. a GalCer — a glyco-lipid originally derived from the marine sponge Agelas mauritianus - was identified because of its potent antitumour effects in mice ${ }^{24}$. a GalCer is an important experimental tool, as it is the main ligand used for functional studies of type I NKT cells because physiological antigens are not as potent or as well characterized. The most commonly used form of a GalCer (also known as KRN7000) comprises an a-linked galactose head group and a ceramide base (consisting of an 18-carbon phytosphingosine chain and a 26-carbon acyl chain) (FIG. 2). Subsequently, a GalCer was shown to bind to human and mouse CD1d and potently activate type I NKT cells ${ }^{24-26}$. 


\section{Type II NKT cells}

Type II NKT cells are CD1d-restricted T cells that lack the 'semi-invariant' TCR a-chain characteristic of type I NKT cells and do not recognize a GalCer ${ }^{4,27}$. Instead, type II NKT cells express a different and more diverse TCR repertoire than type I NKT cells. Although the antigen specificity of type II NKT cells is poorly understood, it includes antigens that are not generally considered to be agonists for type I NKT cells ${ }^{28-30}$. Currently, the most widely studied antigen for type II NKT cells is sulphatide, a sulphated glycolipid that is found abundantly in neuronal tissue and has been associated with the inhibition of experimental autoimmune encephalomyelitis by type II NKT cells ${ }^{28}$. Some biases in TCR chain usage have been described in type II NKT cells. For example, in mice, type II NKT cells appear to be enriched for particular TCR $a$-chain $\mathrm{V}$ segments (namely Va3 and Va8) and for V $\beta 8$ (REF. 31). Furthermore, the TCRs of sulphatide-reactive type II NKT cells can have a more conserved CDR3 $\beta$ region than type I NKT TCRs ${ }^{30}$. Interestingly, a recent study of human sulphatide-reactive type II NKT cells suggested that this population includes some $\mathrm{V} \delta 1^{+} \gamma \delta$ $\mathrm{T}$ cells ${ }^{32}$. The diversity of type II NKT cells highlights the fact that a great deal needs to be learnt about CD1d-restricted antigen specificity and recognition by type II NKT TCRs.

\section{Atypical NKT cells}

Not all NKT cells fit neatly into the current type I-type II NKT cell classification system. Although such atypical NKT cells represent a minor population of the entire NKT cell pool, they can exhibit distinct specificities ${ }^{33,34}$. For example, one atypical NKT cell subset in humans consists of $\mathrm{Va} 24^{-} \mathrm{Ja} 18^{+} \mathrm{V} \beta 11^{+}$cells $^{33-35}$. Another study examined a GalCerreactive $\mathrm{Va} 24^{-}$NKT cell clones from healthy people and showed that, although many clones were enriched for Ja 18 and V $\beta 11$, others exhibited more diverse a $\beta$ TCR usage ${ }^{36}$. The recent characterization of $\mathrm{Va} 10^{+} \mathrm{Ja} 50^{+} \mathrm{V} \beta 8^{+} \mathrm{NKT}$ cells provides a clear example of NKT cells that fall within this grey zone ${ }^{37}$. These NKT cells can respond to a GalCerCD1d, but they show a greater reactivity to a-glucosylceramide (aGlcCer) and preferentially recognize a mycobacterial lipid known as a-glucuronosyldiacylglycerol ${ }^{37}$.

There may also be overlap between type I and type II NKT cell antigens. For example, the self antigen $\beta$-glucosylceramide ( $\beta$ GlcCer) is recognized by both subsets of NKT cells ${ }^{27,38,39}$. Thus, there seems to be a blurring of the boundaries regarding the classification, the antigen specificity and possibly the function of the various NKT cell subsets, and this overlap is likely to be determined, in part, by NKT TCR-mediated recognition. In order to properly understand the function and applications of NKT cells, we need to understand the TCR repertoire and associated antigen specificity of the different subsets of NKT cells.

\section{Antigen presentation by CD1d}

The first crystal structure of a CD1 family member, mouse CD1d, demonstrated that the CD1 family adopts an MHC class I-like fold with a hydrophobic antigen-binding cleft that has deep pockets ideally suited for binding lipid antigens ${ }^{40}$. Subsequently, the crystal structures of CD1a, CD1b, CD1c and CD1d have been determined with various lipid-based antigens bound ${ }^{41-45}$. In general, the CD1 binding cleft is characterized by two main pockets, the $\mathrm{A}^{\prime}$-pocket and the $\mathrm{F}^{\prime}$-pocket (FIG. 2a), which vary in shape and size between CD1 family members ${ }^{46-48}$. This variation, together with their distinct intracellular trafficking behaviour, enables each CD1 isoform to bind to a specific, albeit partly overlapping, repertoire of lipids ${ }^{46,49}$.

The determination of the structure of human CD1d and mouse CD1d in complex with a GalCer (or a closely related analogue ${ }^{17,42,45}$ showed that the acyl chain of a GalCer is buried in the $\mathrm{A}^{\prime}$-pocket of CD1d and the phytosphingosine chain is buried in the $\mathrm{F}^{\prime}$-pocket. 
By contrast, the a-galactosyl head group protrudes from the cleft, such that it is directly available to make contact with the NKT TCR (FIG. 2a). The surface-exposed head group explains why NKT cell agonists include a chemically distinct range of synthetic, foreign and self antigens ${ }^{49,50}$ (FIG. 2b). These antigens can also vary in the nature of the linkage between the head group and the hydrophobic base region, and in the composition of their lipid tails ${ }^{13}$ (FIG. 2b). Such antigenic diversity poses many important questions, which have not been addressed fully. For instance: what determines an optimal NKT cell agonist? How do NKT cells discriminate between self and non-self antigens? Do antigen-specific subsets of NKT cells exist? Understanding the molecular basis of NKT TCR-antigen-CD1d interactions is central to addressing these fundamental questions.

\section{Antigen recognition by type I NKT cells The parallel universe of type I NKT TCR binding}

The fundamental principles underlying the NKT TCR- antigen-CD1d interaction were initially identified from the structure of the human type I Va24-Vß11 NKT TCR-aGalCerCD1d complex ${ }^{51,52}$ (FIG. 3a). The NKT TCR is relatively rigid when binding to aGalCerCD1d ${ }^{18,34,52}$, which exemplifies the innate-like characteristics of this interaction. Of interest, this type I NKT TCR ternary complex is remarkably different to all of the TCRpeptide-MHC class I structures that have been determined so far ${ }^{53,54}$ (FIG. 3a, b). Specifically, the human type I NKT TCR adopts a tilted and parallel docking mode over the $\mathrm{F}^{\prime}$-pocket of CD1d. Highlighting the highly conserved reactivity of type I NKT cells, an almost identical interaction was observed between the mouse type I Va14-V $\beta 8.2$ NKT TCR and aGalCer-CD1d ${ }^{55}$.

At the interface between the human type I Va24-V $\beta 11$ NKT TCR and aGalCer-CD1d, the CDR1a loop interacts with a GalCer, whereas the Ja18-encoded CDR3a loop contacts both CD1d and a GalCer ${ }^{52,55}$ (FIG. 4a). The intimate interactions between the invariant TCR $\mathrm{a}$ chain and the galactose head group of a GalCer provide a basis for understanding the potency of this antigen in stimulating type I NKT cells (FIG. 4a). By contrast, the TCR $\beta$ chain interactions are dominated by two residues (Tyr48 and Tyr50) within the CDR2 $\beta$ loop, which contacts residues above the $\mathrm{F}^{\prime}$-pocket of CD1d ${ }^{52}$ (FIG. 4a). Although several residues within the CDR3a loop are important for binding, Leu99 seems to have a key role in modifying the CD1d interface. Specifically, this residue is inserted into the $\mathrm{F}^{\prime}$-pocket of CD1d, thereby forming a hydrophobic 'roof' that seems to be crucial for NKT TCR binding ${ }^{55-58}$. The energetic basis of the NKT TCR-antigen-CD1d interaction - as defined by residues that, when mutated, have a marked impact on the affinity of the interaction ${ }^{55,59-62}$ - underscores the importance of the CDR2 $\beta$ and CDR3 $a$ loops in driving the antigen-CD1d interaction.

\section{Modulation of TCR-CD1d interactions by the TCR $\alpha$ - and $\beta$-chains}

All of the type I NKT TCR-antigen-CD1d structures elucidated so far have shown that the $\mathrm{F}^{\prime}$-pocket docking orientation is maintained, regardless of TCR $a$ - and $\beta$-chain usage and the nature of the bound antigen ${ }^{10,63-65}$ (FIG. 4; TABLE 1). This reveals that the type I NKT TCR functions like a pattern- recognition receptor - that is, an innate-like, germlineencoded receptor that interacts in a conserved manner with its ligands. For example, in mouse type I NKT cells, TCRs containing V $\beta 8.2, \mathrm{~V} \beta 7$ or $\mathrm{V} \beta 2$ adopt the same docking mode ${ }^{55,62}$, despite sequence variation in the CDR2 $\beta$ loop ${ }^{52,55,62}$. Compensatory interactions are mediated by residues encoded within the respective V $\beta$ gene segments of these NKT TCRs ${ }^{55,62,66}$. Furthermore, additional interactions are mediated by particular CDR3 $\beta$ loops that converge on a focal point within the a2 helix of CD1d $\mathrm{d}^{62,67-70}$ (FIG. 4). This suggests a 
general mechanism pertaining to CD1d-dependent autoreactivity, as the CDR3 $\beta$-mediated interaction does not involve direct contacts with the antigen itself.

Studies have also indicated how the interplay between the germline- and non-germlineencoded regions of the TCR $\beta$-chain could influence the binding of mouse NKT TCRs ${ }^{66}$. Although the TCR $\beta$-chain does not directly contact the glycolipid antigen, variations in TCR $\beta$-chain usage cause subtle structural modifications in the conformation of the TCR achain, which indirectly contribute to the preferential recognition of some antigens ${ }^{55,62}$. This feature may be important in the context of infection and autoreactivity. In addition, although the Ja50-encoded loop of the atypical Va10 NKT TCR is markedly different to the Ja18encoded loop of the Va14 NKT TCR, the Ja50 and Ja18 loops interact with the same region of CD1d. This suggests that other atypical type I NKT TCRs may adopt similar F'pocket docking modes ${ }^{37}$, as has recently been demonstrated with the structure determination of a human Va3.1Ja18 NKT TCR-aGalCer-CD1d complex ${ }^{130}$. Nevertheless, differences have been observed within the respective Va10 and Va14 NKT TCR-antigen-CD1d interfaces (FIG. 4), which provide insights into the molecular basis for the differing ligand specificities of the atypical $\mathrm{Va} 10^{+}$NKT cell subset. These findings highlight the importance of understanding the functional and structural role of atypical type I NKT cells in mice and humans.

\section{Antigens recognized by the type I NKT TCR}

It is clear that, within the confinement of the consensus type I NKT TCR-CD1d footprint ${ }^{10}$ (FIG. 4), the type I NKT TCR binds to a diverse array of chemically distinct antigens. Here, we discuss how the NKT TCR achieves this feat of molecular recognition.

\section{aGalCer and synthetic analogues}

a GalCer can drive both $\mathrm{T}$ helper $1\left(\mathrm{~T}_{\mathrm{H}} 1\right)$-type and $\mathrm{T}_{\mathrm{H}}$ 2-type immune responses, thereby unpredictably causing either enhanced or suppressed immunity ${ }^{5}$. Thus, attention has centred on developing analogues of a GalCer that can bias the immune response in either direction ${ }^{9,13}$. These analogues have modifications in the head group, the acyl chain and/or the sphingosine chain ${ }^{71-74}$. The basis of how such modifications influence NKT TCRmediated recognition has been established for a panel of a GalCer analogues $58,73,75-77$. The consensus type I NKT TCR-CD1d docking topology suggests that NKT cell function can be influenced, in part, by subtle alterations within the NKT TCR-antigen-CD1d interface ${ }^{58}$. As the effects of altered peptide ligands (APLs) on MHC-restricted immunity are associated with minor conformational shifts at the TCR-peptide-MHC interface ${ }^{78}$, we suggest the term 'altered glycolipid ligands' (AGLs) to describe closely related analogues that promote distinct functional NKT cell outcomes ${ }^{58}$.

Many head-group-modified AGLs are differentially recognized by NKT cells and thus have distinct effects on downstream immunity. Although no studies have examined the role of the $2^{\prime}-\mathrm{OH}$ of a GalCer, the distinct orientation of this moiety in a-mannosylceramide (a compound that has very little agonist activity ${ }^{24}$ ) suggests that the $2^{\prime}-\mathrm{OH}$ moiety is crucial for antigen recognition by type I NKT TCRs. AGLs with modifications at the $3^{\prime}-\mathrm{OH}$ and $4^{\prime}-$ $\mathrm{OH}$ positions have fewer contacts with the NKT TCR than a GalCer does and thus are bound by the NKT TCR with lower affinity, resulting in decreased NKT cell activation ${ }^{60,79}$. Interestingly, a GlcCer is a more potent agonist than a GalCer for $\mathrm{Va} 10^{+} \mathrm{Ja}_{50}{ }^{+} \mathrm{NKT}$ cells ${ }^{37}$, highlighting how variations in NKT TCR a-chain usage influence antigen specificity. Further studies of the functional potential of these AGLs are warranted, especially regarding human NKT cells ${ }^{80}$. 
Several AGLs with substitutions or additions at the $6^{\prime}-\mathrm{OH}$ group promote $\mathrm{T}_{\mathrm{H}}$ 1-biased immune responses and provide superior protection against tumour growth in mice ${ }^{73}$. This is reminiscent of the prototypical $\mathrm{T}_{\mathrm{H}} 1$-promoting AGL, a-C-GalCer, and its closely related derivatives ${ }^{72,76}$. Paradoxically, despite their superior anti-tumour and $\mathrm{T}_{\mathrm{H}} 1$-inducing potential, such compounds are bound by the NKT TCR with a lower affinity than aGalCer owing to reduced interactions with the $\mathrm{TCR}^{73,75}$. The superior $\mathrm{T}_{\mathrm{H}} 1$-type response induced by these (and other) ligands ${ }^{77}$ is attributable to the enhanced in vivo ${ }^{73,75}$. Why do stability of the $\mathrm{T}_{\mathrm{H}}$ 1-promoting compounds these compounds lead to $\mathrm{T}_{\mathrm{H}}$ 1-biased responses? When NKT cells are activated, they immediately produce both IFN $\gamma$ and IL-4. However, IL-4 production ceases within a few hours, whereas the production of IFN $\gamma$ continues for 2-3 days and is mostly mediated by bystander natural killer (NK) cells following NKT cell activation ${ }^{72,81}$. This suggests that the lower affinity of the $\mathrm{T}_{\mathrm{H}} 1$-promoting compounds results in lower IL-4 and IFN $\gamma$ levels in the short term, but that the increased stability of these compounds ensures sustained stimulation of NKT cells and NK cells as well as prolonged IFN $\gamma$ production, primarily by the NK cells.

Modifications of the acyl or sphingosine chains of a GalCer can also have an impact on type I NKT cell function ${ }^{82,83}$. For example, two such compounds - known as C20:2 a GalCer (which has an unsaturated acyl chain) and $\mathrm{OCH}$ (which has a truncated sphingosine chain) - promote $\mathrm{T}_{\mathrm{H}}$ 2-biased responses in vivo ${ }^{13}$. The $\mathrm{C} 20: 2$ modification affects neither the affinity nor the mode of interaction with the NKT TCR ${ }^{58}$. This indicates that the $\mathrm{T}_{\mathrm{H}} 2$-biased in vivo cytokine response is primarily due to the very efficient and rapid uptake of C20:2 a GalCer by CD1d-expressing APCs, and also due to the increased turnover of this ligand and less sustained NKT cell activation ${ }^{83}$. Thus, C20:2 a GalCer potently induces short-term NKT cell stimulation and IL-4 and IFN $\gamma$ production, but the long-term activation of NKT cells and bystander NK cells is reduced, leading to decreased IFN $\gamma$ production and an effective bias towards a $\mathrm{T}_{\mathrm{H}}$ 2-type response. A similar mechanism explains the $\mathrm{T}_{\mathrm{H}}$ 2-biased response mediated by $\mathrm{OCH}^{58,81,83,84}$. In this case, however, the truncated sphingosine chain also has an impact on the affinity and association kinetics of the NKT TCR for OCH, as it modulates the architecture of the $\mathrm{F}^{\prime}$-pocket of CD1d ${ }^{58}$ (FIG. 5a).

Overall, the bias towards the production of $\mathrm{T}_{\mathrm{H}} 1$ - or $\mathrm{T}_{\mathrm{H}}$ 2-type cytokines seems to be mainly related to CD1d loading, downstream events, APC types, ligand stability and the pharmacological properties of the AGLs themselves, rather than to altered NKT TCRantigen-CD1d affinity $58,83,85$. However, the affinity of the type I NKT TCR-antigen-CD1d interaction seems to be a good measure of the efficacy of an AGL, in terms of absolute levels of cytokines produced by the NKT cells ${ }^{58}$. Thus, the studies using a GalCer-based AGLs showcase the potential of rationally designing NKT cell agonists that may result in more targeted type I NKT cell-based therapeutic regimens ${ }^{9}$. Moreover, the work carried out using synthetic a GalCer antigens has provided valuable insights into the factors that shape the antigenicity of physiologically relevant ligands.

\section{Microbial ligands}

Microbial lipid antigens that activate type I NKT cells have been identified in a broad range of microorganisms (FIG. 2b). Examples include a-glucuronosylceramides and agalacturonosyl-ceramides from Sphingomonas spp., a-galactosyldiacylglycerols (aGalDAGs) from Borrelia burgdorferi, a-glucosyldiacylglycerols (aGlcDAGs) from Streptococcus pneumoniae and group B Streptococcus, and phosphatidylinositol mannosides (PIMs) from Mycobacterium tuberculosis ${ }^{37,86-92}$.

With the exception of the PIMs, which are phospho-lipids, these bacterial antigens possess a glycosyl head group that is conjugated, via an a-glycosidic linkage, to either a ceramide or a diacylglycerol (DAG) base. The a-glycosidic linkage defines a 'microbial signature', as 
most mammalian glycolipids have $\beta$-glycosidic linkages and, as such, a GalCer is considered to be a mimetic of the microbial a-glycolipids ${ }^{67,89}$. Nonetheless, the structures of these microbial lipid antigens are quite diverse, which highlights the range of foreign antigens that can be recognized by the type I NKT TCR. This recognition is partly achieved by the ability of the NKT TCR to mould the various head groups into a position that facilitates binding ${ }^{67,69}$, as well as by the diversity of the type I NKT TCR provided by the TCR $\beta$-chain 55,75 . As such, some microbial glycolipids seem to be recognized by only a subset of type I NKT cells ${ }^{90-92}$.

Much like in the case of aGalCer analogues, natural variations within the lipid tails of these microbial ligands can dramatically affect their antigenicity, although it is unclear whether this is due to a differential ability to dock into CD1d or due to alterations in CD1d-mediated presentation of the polar head group $57,88,89,93$. In support of the latter scenario, modifications of the DAG chain can determine the orientation of the lipid tails within the A '-pocket and $\mathrm{F}^{\prime}$-pocket of CD1d, thereby affecting the positioning of the glycosyl head group ${ }^{94}$. Furthermore, some microbial ligands leave an 'open' $\mathrm{F}^{\prime}$-pocket in CD1d, which is reshaped (closed) following recognition by the NKT TCR, in a similar manner to NKT TCR-mediated recognition of the a GalCer analogue $\mathrm{OCH}^{56}$ (FIG. 5a). Thus, there seems to be a subtle interplay between the head group and the lipid tails, which - together with type I NKT TCR specificity - ultimately determines the efficacy of the microbial lipid antigens ${ }^{57}$. Clearly, it will be important to establish a broader spectrum of microbial lipid antigens that can stimulate NKT cells and to address whether specific subsets within the NKT repertoire are more ideally tuned to interacting with defined microbial ligands.

\section{Self antigens and NKT cell autoreactivity}

Some NKT cells can respond to CD1d-expressing APCs in the absence of foreign agonist antigens ${ }^{3}$. Indeed, NKT cell-mediated recognition of CD1d-restricted self lipid antigens seems to be important for many immunopathological processes that involve NKT cells, including tumour rejection, autoimmunity, graft rejection and graft-versus-host disease ${ }^{5}$. Furthermore, when combined with pro-inflammatory cytokines, the reactivity of NKT cells to CD1d-restricted self lipids has an important role in NKT cell responses to infection ${ }^{11,38,95,96}$. Self antigens for NKT cells include phospholipid antigens and $\beta$-linked glycolipid antigens, and the relative importance of these molecules appears to be dependent on the cells involved and the presence of inflammatory signals.

\section{Thymic selection by self antigens}

Self-antigen recognition by NKT cells is likely to be imprinted in the thymus, where the recognition of CD1d-restricted self antigens is crucial for the intrathymic selection and survival of these cells ${ }^{97}$, similarly to the positive selection of T cells by self-peptide-MHC complexes ${ }^{98}$. Thus, the identification of the self lipid antigens that are involved in intrathymic NKT cell selection is a central goal. One candidate self lipid isoglobotrihexosylceramide (iGb3) - is a moderate agonist for type I NKT cells ${ }^{99}$, although it remains controversial whether iGb3 is involved in NKT cell selection in mice or humans ${ }^{100-103}$. More recently, Facciotti et al. provided evidence that two peroxisomegenerated, ether-bonded phospholipid antigens - plasmalogen lysophosphatidylethanolamine (pLPE) and ether lysophosphatidic acid (eLPA) - have a role in NKT cell development ${ }^{104}$. pLPE was capable of strongly activating type I NKT cells, and mice deficient in these peroxisomal lipids had impaired NKT cell development. It is quite possible that NKT cells are selected by a range of lipid-based antigens, including glycolipids and phospholipids, and that a level of redundancy exists in this process. Understanding the precise metabolic pathways involved in the generation of such self antigens will be central for determining whether different self antigens have unique roles in 
NKT cell biology, as well as for addressing how NKT TCRs recognize these structurally distinct self antigens.

\section{Self-glycolipid recognition}

Most mammalian glycolipids possess a $\beta$-linked glycolipid head group that protrudes from $\mathrm{CD} 1 \mathrm{~d}$, in contrast to the 'flattened' conformation of the a-linked ligands ${ }^{105,106}$ (FIGS 3a, $5 b)$. The study of NKT TCRs in complex with $\beta$-galactosylceramide ( $\beta$ GalCer) and iGb3 has provided insights into how type I NKT TCRs can recognize such distinct structural landscapes. Specifically, the NKT TCRs flatten the $\beta$-linked glycolipid head groups into a conformation that mirrors that of the a-linked antigens ${ }^{67,69}$ (FIG. 5b). This flattening of self antigens is reminiscent of the 'bulldozer-like' effect observed in some MHC-restricted T cell responses ${ }^{107-109}$ and reveals that, for the recognition of $\beta$-linked ligands, type I NKT TCRs operate through induced-fit molecular mimicry (FIG. 4a). In comparison to the NKT TCRmediated recognition of a-linked antigens, the interactions between type I NKT TCRs and $\beta$-linked antigen-CD1d complexes are of considerably lower affinity ${ }^{67,69}$. This weak reactivity may be important for selecting an appropriate NKT TCR repertoire during development, so as to avoid overt NKT cell-mediated autoimmunity while ensuring the generation of an NKT cell repertoire that is poised for activation by foreign antigens.

\section{Self-phospholipid recognition}

Phospholipids represent a major component of biological membranes and thus are highly abundant but also extremely heterogeneous. Phospholipid self antigens for type I NKT cells include phosphatidylethanolamine, phosphatidylinositol ${ }^{95,104,110}$ and pLPE $^{104}$. The structure of an engineered autoreactive type I NKT TCR-phosphatidylinositol-CD1d complex was shown to be very similar to that of type I NKT TCR-glycolipid-CD1d complexes ${ }^{68}$. The main difference was in the positioning of the phosphatidylinositol head group, which was orientated away from the NKT TCR-CD1d interface. Recently, the structure of a human type I NKT TCR-lysophosphatidylcholine-CD1d complex was elucidated, showing that the phosphatidylcholine head group shifts conformation markedly following the ligation of the type I NKT TCR ${ }^{70}$. This shift enables the formation of the consensus type I NKT TCR-CD1d docking topology, although there seems to be a slight 'wobble' in the overall docking topology in relation to other type I NKT TCR-CD1d complexes.

\section{Mechanisms of self-antigen recognition}

The reactivity of type I NKT cells to self antigens is strongly influenced by the TCR $\beta$ chain, which can affect the fine specificity of the NKT TCR $55,61,62,66,68,111$. Diversity within the CDR3 $\beta$ loop can engender CD1d-mediated autoreactivity by facilitating the direct interaction of this loop with CD1d ${ }^{68,111}$ (FIG. 4a), thereby reducing the specific energetic contribution required from the self antigens for interaction with the NKT TCR. Moreover, residues within the TCR $\beta$-chain can have an impact on the conformation of the invariant TCR $\alpha$-chain, thereby indirectly modulating NKT TCR-antigen contacts ${ }^{55,70}$. These effects may explain the variability in the extent to which NKT TCRs can engage self antigens. Accordingly, multiple self antigens are recognized in a similar manner by these autoreactive type I NKT TCRs. Nevertheless, some CD1d-bound self glycolipids, such as the disialoganglioside GD3, can apparently 'thwart' the binding of the type I NKT TCR ${ }^{68}$, presumably through steric hindrance or charge repulsion. As CD1d molecules at the surface of APCs are likely to be loaded with a variety of self antigens with differing chemistries ${ }^{112}$, type I NKT cell autoreactivity caused by CDR3 $\beta$ loop diversity may be attributable to a shift in the balance between permissive and non-permissive self antigens. 
Is autoreactivity limited to a subset of type I NKT TCRs with appropriate 'autoreactive' CDR3 $\beta$ loops? Given that all NKT cells are positively selected in the thymus, it is likely that they are all capable of interacting with self-antigen-CD1d complexes to some extent and that some self antigens may directly contribute to autoreactivity, regardless of CDR3 $\beta$ CD1d interactions. These self antigens need not be strong agonists, and there may be heterogeneous lipid antigen species that support these processes in different settings, potentially with a differential role for type I and type II NKT cells. For example, the lowaffinity self antigens $\beta$ GlcCer and LPE are upregulated during bacterial and hepatitis B virus infections, respectively, resulting in NKT cell activation owing to the increased avidity of NKT TCR-antigen-CD1d binding combined with the presence of pro-inflammatory cytokines that co-stimulate these cells ${ }^{38,95}$. This illustrates two important concepts: first, that NKT cells are indirectly sensitized to microbial danger signals via the modulation of self lipid antigens presented by CD1d; and, second, that different self antigens may be important in different settings.

The factors that govern the antigenicity of specific ligands for type I and type II NKT cells are currently unclear, although the closely related nature of these antigens suggests that antigen density and CD1d-loading efficiency may be important factors in NKT cell autoreactivity ${ }^{70,95,104,113-116}$. Overall, NKT cell autoreactivity remains a poorly understood area of NKT cell biology, and - considering that it is likely to be central for NKT cell responses in health and disease - it represents a key area for further investigation.

\section{Type II NKT TCR-mediated recognition}

Our understanding of the specificity and function of type II NKT cells is limited, and this is largely due to a lack of reagents to directly study this NKT cell subset. Do type I and type II NKT cells represent functionally similar cells with distinct antigen specificities or do they also mediate different immunological functions following activation? In support of the latter possibility, type I NKT cells are usually associated with the promotion of tumour rejection in mice, whereas type II NKT cells seem to suppress tumour rejection in mice and can antagonize the functions of type I NKT cells ${ }^{117}$. In a more recent study, type I and type II NKT cells seemed to work together in protecting against hepatitis B virus infection in mice ${ }^{95}$. Central to our understanding of the role of type II NKT cells in immunity is the establishment of their antigen specificity and the way in which their TCRs recognize these CD1d-presented antigens.

A key question is whether type II NKT TCRs adopt a different docking strategy from type I NKT TCRs. Two recent studies have provided the first snapshot of type II NKT TCRmediated recognition, by determining the ternary structure of a type II NKT TCR (Va1Ja26-V $\beta 16 J 32.1$ ) in complex with sulphatide-CD1d ${ }^{118}$ or lysosulphatide-CD1d ${ }^{119}$. Despite the difference in these forms of sulphatide, the docking modes of the type II NKT TCR were remarkably similar to each other. The type II NKT TCR docked orthogonally above the $\mathrm{A}^{\prime}$-pocket of CD1d, and the complex was thus distinct from all type I NKT TCR complexes ${ }^{10}$ (FIGS 3,4). Unlike the recognition of $\beta$-linked glycolipids by the type I NKT $\mathrm{TCR}^{67}$, the type II NKT TCR does not 'flatten' the sulphatide head group during ligation, although the positioning of the sulphatide head groups in the two type II ternary complexes was slightly different, suggesting a degree of flexibility in type II NKT TCR-mediated recognition. Moreover, the CDR3 loops of this TCR dominate the interaction, with the CDR $3 a$ and CDR $3 \beta$ loops interacting primarily with CD1d and sulphatide, respectively ${ }^{118}$ (FIG. 4b). These findings will fuel speculation as to whether all type II NKT TCRs dock over the $\mathrm{A}^{\prime}$-pocket, or whether the diverse type II NKT cell repertoire results in a myriad of distinct docking modes. Consistent with the latter possibility, mutagenesis studies of TCRs from other type II NKT cell clones have suggested that these TCRs have distinct docking 
footprints $25,29,118-120$. These initial studies suggest that type II NKT TCR-mediated antigen recognition is fundamentally distinct from type I NKT TCR-mediated recognition.

\section{NKT cell recognition: implications for therapy}

Great progress has been made since the discovery that a GalCer is an antigen for type I NKT cells ${ }^{24}$. Despite the very high affinity of the interaction with this antigen and its obvious therapeutic potential as an NKT cell agonist ${ }^{9}$, the physiological antigens for NKT cells are self lipid molecules that are recognized with much lower affinity ${ }^{38}$. For type I NKT cells, the antigen must be presented by CD1d in such a way that the polar head group can either contribute to the interaction or be flattened in a manner that does not destabilize the conserved interaction that defines all type I NKT TCR-antigen-CD1d complexes. Moreover, in the context of $\beta$-linked ligand recognition, we have shown that the antigenicity of a ligand is attributable to compensatory interactions between CD1d and the ligand itself that occur after NKT TCR ligation ${ }^{67}$ (FIG. 5b). Collectively, ligand antigenicity is determined by multiple factors, including the composition of the polar head group and lipid tails, ligand flexibility, and the ability of the ligand to be stabilized by either the NKT TCR or CD1d. The same variables may influence antigen recognition by type II NKT cells, with the important distinction that the greater TCR diversity within this population may facilitate a greater diversity in antigen recognition and TCR docking modes. The observation that type II NKT cells do not recognize a GalCer, despite its potency for activating type I NKT cells, highlights the fact that these two lineages are not redundant, although some antigens may be capable of activating both type I and type II NKT cells ${ }^{27,38}$.

Given that NKT cells can be activated by self antigens, the question that arises is how NKT cells normally avoid overt autoreactivity. It seems that, in steady-state conditions, the amount of signalling induced by self lipid antigens is insufficient to trigger NKT cell activation. However, modulation of the biosynthesis or degradation of self lipids, combined with increased co-stimulatory signalling, enables NKT cells to act as an early warning system for infections ${ }^{38,95}$ (FIG. 6). Similar mechanisms may explain NKT cell responses to tumours and in auto-immune diseases. Nonetheless, only some self antigens are capable of promoting NKT cell activation under these circumstances ${ }^{38,95,110}$, suggesting that lowaffinity interactions with the NKT TCR are important factors in this process. Lastly, if NKT cell activation can be driven by the modulation of self-antigen expression, what is the significance of high-affinity, a-linked foreign antigens such as a GalCer in NKT cell biology? The difference in TCR signal strength is likely to result in distinct NKT cell functional programmes and, as such, have a differential impact on downstream effector responses. It is also possible that, for NKT cell activation, a small number of high-affinity antigens might be complemented by more abundant low-affinity self antigens, much like what is seen with peptide-MHC reactivity in conventional T cells ${ }^{121}$.

NKT cells can have both beneficial and deleterious roles in the immune system. NKT cells can enhance immunity to infection and some forms of cancer, and they are capable of protecting against graft-versus-host disease, allograft rejection and some types of autoimmunity ${ }^{5}$. In other settings, however, NKT cells can be activated in response to lipid allergens found in house dust extract ${ }^{12}$ or pollen ${ }^{122}$ and trigger allergic responses and airway hyperreactivity ${ }^{123}$. Similarly, the activation of NKT cells by circulating lipid antigens that are associated with atherosclerosis contributes to cardiovascular disease ${ }^{124}$, and NKT cell activation can also exacerbate some forms of autoimmune disease and prevent the efficient clearance of tumour cells in some models of cancer ${ }^{5,117}$. Thus, although the therapeutic potential of NKT cells is broad, the influence of these cells in different disease settings is complicated and unpredictable. Nevertheless, despite these challenges, recent clinical trials involving combination therapy using both a GalCer-pulsed autologous DCs and in vitro- 
expanded autologous NKT cells resulted in an increase in NKT cell frequency and improved anti-tumour immunity in a cohort of patients suffering from head and neck squamous cell carcinoma $^{125,126}$. Such studies highlight the fact that it is vital that we gain a better understanding of the functions of the different types of NKT cells, as well as of the influence of different classes of antigens and other microenvironmental factors on these cells, in order to safely harness their therapeutic potential.

\section{Future directions}

There are fundamental differences between the recognition of lipid-based antigens by the a $\beta$ TCRs of type I NKT cells and the interaction of peptide-based antigens with the TCRs of conventional T cells. Our understanding of lipid antigen recognition by type I NKT TCRs has progressed markedly in recent years and has provided valuable insights into the factors that govern antigenicity and the functional impact of different types of antigen. This in turn helps us to understand the natural antigenic targets of NKT cells and informs the development of superior and more tailored therapeutic reagents to harness NKT cell activity. There are many outstanding questions, including whether minor subsets of antigen-specific NKT cells can undergo clonal expansion and develop into memory-like populations. Moreover, what determines the threshold of NKT cell self-tolerance versus self-reactivity? Do NKT cells with distinct antigen specificities, such as type I and type II NKT cells, accordingly exhibit distinct functions? Addressing these questions is not only crucial for our understanding of NKT cell biology, but also central to the development of effective therapeutics.

Notably, CD1d-restricted NKT cells represent only a small subset of lipid-reactive T cells in humans ${ }^{1}$. There are also $\mathrm{T}$ cells that recognize lipids presented by group $1 \mathrm{CD} 1$ molecules, as well as other subsets of innate-like T cells, such as MR1-restricted mucosa-associated invariant T cells (MAIT cells) - which have recently been shown to recognize microbial vitamin B metabolites ${ }^{131}$ — and $\gamma \delta \mathrm{T}$ cells. These T cell subsets collectively represent $10 \%$ or more of the peripheral blood mono-nuclear cells in humans and an even higher proportion of the total leukocyte population found in tissues such as the gut and liver. Considering this, it is clear that there remains an enormous amount to learn about this important $\mathrm{T}$ cell arm of the immune system ${ }^{127-129}$.

\section{Acknowledgments}

This work was supported by the US National Institutes of Health (grants AI090450 and AI092108), Australian National Health and Medical Research Council (NHMRC) program and project grants, Cancer Council Victoria and the Australian Research Council (ARC). D.I.G. was supported by an NHMRC Senior Principal Research Fellowship; J.R. was supported by an NHMRC Australia Fellowship. O.P. was supported by an ARC Future Fellowship.

\section{Glossary}

$\gamma \delta \mathrm{T}$ cells
Altered peptide ligands (APLs)

T cells express either a $\mathrm{T}$ cell receptor (TCR) composed of $\alpha$ - and $\beta$ subunits (a $\beta$ TCR) or a TCR composed of $\gamma$ - and $\delta$-subunits ( $\gamma \delta$ TCR). The majority (more than 90\%) of human T cells express $\alpha \beta$ TCRs, which mainly recognize antigenic peptides bound to conventional MHC class I or II molecules. T cells that express $\gamma \delta$ TCRs are less abundant, and the ligands for these receptors are less well characterized

Peptides that are analogues of an original antigenic peptide. They commonly have amino acid substitutions at residues that make contact with the T cell receptor (TCR). TCR engagement by these APLs 
usually leads to partial or incomplete T cell activation. Some APLs (antagonists) can specifically antagonize and inhibit $\mathrm{T}$ cell activation by the wild-type antigenic peptide

Peroxisome

Mucosa-
associated
invariant T
cells (MAIT
cells)

An indispensable cytoplasmic organelle that has essential roles in antioxidant defence, cholesterol and bile-acid synthesis, eicosanoid metabolism and the $\beta$ - and $\omega$-oxidation of long-chain and very-longchain fatty acids

A population of innate-like lymphocytes. MAIT cells express an evolutionarily conserved invariant $\mathrm{T}$ cell receptor and are selected by the MHC class I-related molecule MR1. They are abundant in human blood, in the intestinal mucosa and in mesenteric lymph nodes, and they can produce interferon- $\gamma$ in response to various bacterial infections

\section{References}

1. Brigl M, Brenner MB. CD1: antigen presentation and T cell function. Annu Rev Immunol. 2004; 22:817-890. [PubMed: 15032598]

2. Mori L, De Libero G. T cells specific for lipid antigens. Immunol Res. 2012; 53:191-199. [PubMed: 22427014]

3. Bendelac A, Savage PB, Teyton L. The biology of NKT cells. Annu Rev Immunol. 2007; 25:297336. [PubMed: 17150027]

4. Godfrey DI, MacDonald HR, Kronenberg M, Smyth MJ, Van Kaer L. NKT cells: what's in a name? Nature Rev Immunol. 2004; 4:231-237. [PubMed: 15039760]

5. Godfrey DI, Kronenberg M. Going both ways: immune regulation via CD1d-dependent NKT cells. J Clin Invest. 2004; 114:1379-1388. [PubMed: 15545985]

6. Matsuda JL, Mallevaey T, Scott-Browne J, Gapin L. CD1d-restricted iNKT cells, the 'Swiss-Army knife' of the immune system. Curr Opin Immunol. 2008; 20:358-368. [PubMed: 18501573]

7. Berzins SP, Smyth MJ, Baxter AG. Presumed guilty: natural killer T cell defects and human disease. Nature Rev Immunol. 2011; 11:131-142. [PubMed: 21267014]

8. Cerundolo V, Barral P, Batista FD. Synthetic iNKT cell-agonists as vaccine adjuvants - finding the balance. Curr Opin Immunol. 2010; 22:417-424. [PubMed: 20471232]

9. Cerundolo V, Silk JD, Masri SH, Salio M. Harnessing invariant NKT cells in vaccination strategies. Nature Rev Immunol. 2009; 9:28-38. [PubMed: 19079136]

10. Godfrey DI, et al. Antigen recognition by CD1d-restricted NKT T cell receptors. Semin Immunol. 2010; 22:61-67. [PubMed: 19945889]

11. Godfrey DI, Rossjohn J. New ways to turn on NKT cells. J Exp Med. 2011; 208:1121-1125. [PubMed: 21646400]

12. Wingender $\mathrm{G}$, et al. Invariant NKT cells are required for airway inflammation induced by environmental antigens. J Exp Med. 2011; 208:1151-1162. [PubMed: 21624935]

13. Venkataswamy MM, Porcelli SA. Lipid and glycolipid antigens of CD1d-restricted natural killer T cells. Semin Immunol. 2010; 22:68-78. [PubMed: 19945296]

14. Dellabona P, Padovan E, Casorati G, Brockhaus M, Lanzavecchia A. An invariant Va24-JaQ/ $\mathrm{V} \beta 11 \mathrm{~T}$ cell receptor is expressed in all individuals by clonally expanded CD4- $8^{-} \mathrm{T}$ cells. $\mathrm{J}$ Exp Med. 1994; 180:1171-1176. [PubMed: 8064234]

15. Porcelli S, Yockey CE, Brenner MB, Balk SP. Analysis of T cell antigen receptor (TCR) expression by human peripheral blood $\mathrm{CD}^{-} 8^{-} \mathrm{a} / \beta \mathrm{T}$ cells demonstrates preferential use of several V $\beta$ genes and an invariant TCR a chain. J Exp Med. 1993; 178:1-16. [PubMed: 8391057]

16. Lantz $\mathrm{O}$, Bendelac A. An invariant $\mathrm{T}$ cell receptor a chain is used by a unique subset of major histocompatibility complex class I-specific $\mathrm{CD} 4^{+}$and $\mathrm{CD}^{-} 8^{-} \mathrm{T}$ cells in mice and humans. $\mathrm{J}$ Exp Med. 1994; 180:1097-1106. [PubMed: 7520467] 
17. Godfrey DI, McCluskey J, Rossjohn J. CD1d antigen presentation: treats for NKT cells. Nature Immunol. 2005; 6:754-756. [PubMed: 16034430]

18. Kjer-Nielsen L, et al. A structural basis for selection and cross-species reactivity of the semiinvariant NKT cell receptor in CD1d/glycolipid recognition. J Exp Med. 2006; 203:661-673. [PubMed: 16505140]

19. Brossay L, et al. Cd1d-mediated recognition of an a-galactosylceramide by natural killer $\mathrm{T}$ cells is highly conserved through mammalian evolution. J Exp Med. 1998; 188:1521-1528. [PubMed: 9782129]

20. Cui JQ, et al. Requirement for Va14 NKT cells in IL-12-mediated rejection of tumors. Science. 1997; 278:1623-1626. [PubMed: 9374462]

21. Bedel R, et al. Lower TCR repertoire diversity in Traj18-deficient mice. Nature Immunol. 2012; 13:705-706. [PubMed: 22814339]

22. Matsuda JL, et al. Natural killer T cells reactive to a single glycolipid exhibit a highly diverse T cell receptor $\beta$ repertoire and small clone size. Proc Natl Acad Sci USA. 2001; 98:12636-12641. [PubMed: 11592984]

23. Gapin L. iNKT cell autoreactivity: what is 'self' and how is it recognized? Nature Rev Immunol. 2010; 10:272-277. [PubMed: 20224567]

24. Kawano T, et al. CD1d-restricted and TCR-mediated activation of Va14 NKT cells by glycosylceramides. Science. 1997; 278:1626-1629. This study characterizes a-galactosylceramide as a ligand for type I NKT cells. [PubMed: 9374463]

25. Burdin N, et al. Structural requirements for antigen presentation by mouse CD1. Proc Natl Acad Sci USA. 2000; 97:10156-10161. [PubMed: 10963678]

26. Burdin N, et al. Selective ability of mouse CD1 to present glycolipids: a-galactosylceramide specifically stimulates Va14+ NK T lymphocytes. J Immunol. 1998; 161:3271-3281. [PubMed: 9759842]

27. Rhost S, Sedimbi S, Kadri N, Cardell SL. Immunomodulatory type II natural killer T (NKT) lymphocytes in health and disease. Scand J Immunol. 2012; 76:246-255. [PubMed: 22724893]

28. Jahng A, et al. Prevention of autoimmunity by targeting a distinct, noninvariant CD1d-reactive T cell population reactive to sulfatide. J Exp Med. 2004; 199:947-957. [PubMed: 15051763]

29. Cardell S, et al. CD1-restricted CD4 ${ }^{+}$T cells in major histocompatibility complex class II-deficient mice. J Exp Med. 1995; 182:993-1004. [PubMed: 7561702]

30. Arrenberg P, Halder R, Dai Y, Maricic I, Kumar V. Oligoclonality and innate-like features in the TCR repertoire of type II NKT cells reactive to a $\beta$-linked self-glycolipid. Proc Natl Acad Sci USA. 2010; 107:10984-10989. [PubMed: 20534460]

31. Park SH, et al. The mouse CD1d-restricted repertoire is dominated by a few autoreactive T cell receptor families. J Exp Med. 2001; 193:893-904. [PubMed: 11304550]

32. Bai L, et al. The majority of CD1d-sulfatide-specific T cells in human blood use a semiinvariant V81 TCR. Eur J Immunol. 2012; 42:2505-2510. [PubMed: 22829134]

33. Gadola SD, Dulphy N, Salio M, Cerundolo V. Va24-JaQ-independent, CD1d-restricted recognition of a-galactosylceramide by human $\mathrm{CD}^{+}{ }^{+}$and $\mathrm{CD} 8 \mathrm{a} \beta^{+} \mathrm{T}$ lymphocytes. J Immunol. 2002; 168:5514-5520. [PubMed: 12023346]

34. Gadola SD, et al. Structure and binding kinetics of three different human CD1d-agalactosylceramide-specific T cell receptors. J Exp Med. 2006; 203:699-710. [PubMed: 16520393]

35. Brigl M, et al. Conserved and heterogeneous lipid antigen specificities of CD1d-restricted NKT cell receptors. J Immunol. 2006; 176:3625-3634. [PubMed: 16517731]

36. Constantinides MG, Picard D, Savage AK, Bendelac AA. Naive-like population of human CD1drestricted T cells expressing intermediate levels of promyelocytic leukemia zinc finger. J Immunol. 2011; 187:309-315. [PubMed: 21632718]

37. Uldrich AP, et al. A semi-invariant $\mathrm{Va}_{10}{ }^{+} \mathrm{T}$ cell antigen receptor defines a population of natural killer T cells with distinct glycolipid antigen-recognition properties. Nature Immunol. 2011; 12:616-623. [PubMed: 21666690]

38. Brennan PJ, et al. Invariant natural killer T cells recognize lipid self antigen induced by microbial danger signals. Nature Immunol. 2011; 12:1202-1211. This study shows that a particular form of 
$\beta$ GlcCer represents a self ligand for the NKT TCR that is upregulated during infection. [PubMed: 22037601]

39. Rhost $\mathrm{S}$, et al. Identification of novel glycolipid ligands activating a sulfatide reactive, CD1drestricted, type II natural killer T lymphocyte. Eur J Immunol. Jul 10.2012 10.1002/eji.201142350

40. Zeng Z, et al. Crystal structure of mouse CD1: an MHC-like fold with a large hydrophobic binding groove. Science. 1997; 277:339-345. [PubMed: 9219685]

41. Gadola SD, et al. Structure of human CD1b with bound ligands at $2.3 \AA$, a maze for alkyl chains. Nature Immunol. 2002; 3:721-726. [PubMed: 12118248]

42. Zajonc DM, et al. Structure and function of a potent agonist for the semi-invariant natural killer T cell receptor. Nature Immunol. 2005; 6:810-818. [PubMed: 16007091]

43. Zajonc DM, Elsliger MA, Teyton L, Wilson IA. Crystal structure of CD1a in complex with a sulfatide self antigen at a resolution of $2.15 \AA$. Nature Immunol. 2003; 4:808-815. [PubMed: 12833155]

44. Scharf L, et al. The $2.5 \AA$ structure of CD1c in complex with a mycobacterial lipid reveals an open groove ideally suited for diverse antigen presentation. Immunity. 2010; 33:853-862. [PubMed: 21167756]

45. Koch M, et al. The crystal structure of human CD1d with and without a-galactosylceramide. Nature Immunol. 2005; 6:819-826. [PubMed: 16007090]

46. Moody DB, Zajonc DM, Wilson IA. Anatomy of CD1-lipid antigen complexes. Nature Rev Immunol. 2005; 5:387-399. [PubMed: 15864273]

47. Zajonc DM, Wilson IA. Architecture of CD1 proteins. Curr Top Microbiol Immunol. 2007; 314:27-50. [PubMed: 17593656]

48. Salio M, Silk JD, Cerundolo V. Recent advances in processing and presentation of CD1 bound lipid antigens. Curr Opin Immunol. 2010; 22:81-88. [PubMed: 20080041]

49. Cohen NR, Garg S, Brenner MB. Antigen presentation by CD1: lipids, T cells, and NKT cells in microbial immunity. Adv Immunol. 2009; 102:1-94. [PubMed: 19477319]

50. Brutkiewicz RR. CD1d ligands: the good, the bad, and the ugly. J Immunol. 2006; 177:769-775. [PubMed: 16818729]

51. Borg NA, Kjer-Nielsen L, McCluskey J, Rossjohn J. Structural insight into natural killer T cell receptor recognition of CD1d. Adv Exp Med Biol. 2007; 598:20-34. [PubMed: 17892202]

52. Borg NA, et al. CD1d-lipid-antigen recognition by the semi-invariant NKT T-cell receptor. Nature. 2007; 448:44-49. This study provides the first description of a type I NKT TCR-antigenCD1d interaction. [PubMed: 17581592]

53. Godfrey DI, Rossjohn J, McCluskey J. The fidelity, occasional promiscuity, and versatility of T cell receptor recognition. Immunity. 2008; 28:304-314. [PubMed: 18342005]

54. Burrows SR, et al. Hard wiring of T cell receptor specificity for the major histocompatibility complex is underpinned by TCR adaptability. Proc Natl Acad Sci USA. 2010; 107:10608-10613. [PubMed: 20483993]

55. Pellicci DG, et al. Differential recognition of CD1d- $a$-galactosyl ceramide by the V $\beta 8.2$ and V $\beta 7$ semi-invariant NKT T cell receptors. Immunity. 2009; 31:47-59. [PubMed: 19592275]

56. Li Y, et al. The Va14 invariant natural killer T cell TCR forces microbial glycolipids and CD1d into a conserved binding mode. J Exp Med. 2010; 207:2383-2393. This report provided the first insights into how the type I NKT TCR can interact with microbial ligands. [PubMed: 20921281]

57. Girardi E, et al. Unique interplay between sugar and lipid in determining the antigenic potency of bacterial antigens for NKT cells. PLoS Biol. 2011; 9:e1001189. [PubMed: 22069376]

58. Wun KS, et al. A molecular basis for the exquisite CD1d-restricted antigen specificity and functional responses of natural killer T cells. Immunity. 2011; 34:327-339. [PubMed: 21376639]

59. Scott-Browne JP, et al. Germline-encoded recognition of diverse glycolipids by natural killer T cells. Nature Immunol. 2007; 8:1105-1113. This study showed for the first time how the type I NKT TCR can function like a pattern-recognition receptor. [PubMed: 17828267]

60. Wun KS, et al. A minimal binding footprint on CD1d-glycolipid is a basis for selection of the unique human NKT TCR. J Exp Med. 2008; 205:939-949. [PubMed: 18378792] 
61. Florence WC, et al. Adaptability of the semi-invariant natural killer T-cell receptor towards structurally diverse CD1d-restricted ligands. EMBO J. 2009; 28:3579-3590. [PubMed: 19816402]

62. Patel O, et al. Vb2 natural killer T cell antigen receptor-mediated recognition of CD1d-glycolipid antigen. Proc Natl Acad Sci USA. 2011; 108:19007-19012. [PubMed: 22065767]

63. Joyce S, Girardi E, Zajonc DM. NKT cell ligand recognition logic: molecular basis for a synaptic duet and transmission of inflammatory effectors. J Immunol. 2011; 187:1081-1089. [PubMed: 21772035]

64. Mallevaey T, Selvanantham T. Strategy of lipid recognition by invariant natural killer T cells: 'one for all and all for one'. Immunology. 2012; 136:273-282. [PubMed: 22671023]

65. Adams EJ, Lopez-Sagaseta J. The immutable recognition of CD1d. Immunity. 2011; 34:281-283. [PubMed: 21435579]

66. Mallevaey T, et al. T cell receptor CDR2 $\beta$ and CDR3 $\beta$ loops collaborate functionally to shape the iNKT cell repertoire. Immunity. 2009; 31:60-71. [PubMed: 19592274]

67. Pellicci DG, et al. Recognition of $\beta$-linked self glycolipids mediated by natural killer $\mathrm{T}$ cell antigen receptors. Nature Immunol. 2011; 12:827-833. [PubMed: 21804559]

68. Mallevaey T, et al. A molecular basis for NKT cell recognition of CD1d-self-antigen. Immunity. 2011; 34:315-326. This report provided the first structural insights into the basis of CD1dmediated autoreactivity. [PubMed: 21376640]

69. Yu ED, Girardi E, Wang J, Zajonc DM. Cutting edge: structural basis for the recognition of $\beta$ linked glycolipid antigens by invariant NKT cells. J Immunol. 2011; 187:2079-2083. Together with reference 67 , this study showed that the type I NKT TCR can 'bulldoze' $\beta$-linked ligands to enable CD1d engagement. [PubMed: 21810611]

70. Lopez-Sagaseta J, Sibener LV, Kung JE, Gumperz J, Adams EJ. Lysophospholipid presentation by CD1d and recognition by a human natural killer T-cell receptor. EMBO J. 2012; 31:2047-2059. This is the first description of how an NKT TCR can recognize lysophospholipids. [PubMed: 22395072]

71. Miyamoto K, Miyake S, Yamamura T. A synthetic glycolipid prevents autoimmune encephalomyelitis by inducing $\mathrm{T}_{\mathrm{H}} 2$ bias of natural killer T cells. Nature. 2001; 413:531-534. [PubMed: 11586362]

72. Schmieg J, Yang G, Franck RW, Tsuji M. Superior protection against malaria and melanoma metastases by a C-glycoside analogue of the natural killer $\mathrm{T}$ cell ligand a-galactosylceramide. $\mathrm{J}$ Exp Med. 2003; 198:1631-1641. [PubMed: 14657217]

73. Aspeslagh S, et al. Galactose-modified iNKT cell agonists stabilized by an induced fit of CD1d prevent tumour metastasis. EMBO J. 2011; 30:2294-2305. [PubMed: 21552205]

74. Yu KO, et al. Modulation of CD1d-restricted NKT cell responses by using $N$-acyl variants of agalactosylceramides. Proc Natl Acad Sci USA. 2005; 102:3383-3388. [PubMed: 15722411]

75. Patel O, et al. NKT TCR recognition of CD1d- $\mathbf{a}$ - $C$-galactosylceramide. J Immunol. 2011; 187:4705-4713. [PubMed: 21964029]

76. Kerzerho J, et al. Structural and functional characterization of a novel nonglycosidic type I NKT agonist with immunomodulatory properties. J Immunol. 2012; 188:2254-2265. [PubMed: 22301545]

77. Tyznik AJ, et al. Glycolipids that elicit IFN- $\gamma$-biased responses from natural killer T cells. Chem Biol. 2011; 18:1620-1630. [PubMed: 22195564]

78. Sloan-Lancaster J, Allen PM. Altered peptide ligand-induced partial T cell activation: molecular mechanisms and role in T cell biology. Annu Rev Immunol. 1996; 14:1-27. [PubMed: 8717505]

79. Raju R, et al. Synthesis and evaluation of 3 " - and 4"-deoxy and -fluoro analogs of the immunostimulatory glycolipid, KRN7000. Bioorg Med Chem Lett. 2009; 19:4122-4125. [PubMed: 19535248]

80. Wun KS, et al. Human and mouse type I natural killer T-cell antigen receptors exhibit different fine specificities for CD1d-antigen. J Biol Chem. Sep 20.2012 10.1074/jbc.M112.412320

81. Sullivan BA, et al. Mechanisms for glycolipid antigen-driven cytokine polarization by Va14i NKT cells. J Immunol. 2010; 184:141-153. [PubMed: 19949076] 
82. McCarthy C, et al. The length of lipids bound to human CD1d molecules modulates the affinity of NKT cell TCR and the threshold of NKT cell activation. J Exp Med. 2007; 204:1131-1144. [PubMed: 17485514]

83. Im JS, et al. Kinetics and cellular site of glycolipid loading control the outcome of natural killer T cell activation. Immunity. 2009; 30:888-898. This study shows how mechanisms pertaining to antigen loading can relate to the efficacy of an antigen in activating NKT cells. [PubMed: 19538930]

84. Bai L, et al. Lysosomal recycling terminates CD1d- mediated presentation of short and polyunsaturated variants of the NKT cell lipid antigen aGalCer. Proc Natl Acad Sci USA. 2009; 106:10254-10259. [PubMed: 19506241]

85. Bai L, et al. Distinct APCs explain the cytokine bias of a-galactosylceramide variants in vivo. J Immunol. 2012; 188:3053-3061. [PubMed: 22393151]

86. Mattner J, et al. Exogenous and endogenous glycolipid antigens activate NKT cells during microbial infections. Nature. 2005; 434:525-529. [PubMed: 15791258]

87. Sriram V, Du W, Gervay-Hague J, Brutkiewicz RR. Cell wall glycosphingolipids of Sphingomonas paucimobilis are CD1d-specific ligands for NKT cells. Eur J Immunol. 2005; 35:1692-1701. [PubMed: 15915536]

88. Kinjo Y, et al. Invariant natural killer T cells recognize glycolipids from pathogenic Gram-positive bacteria. Nature Immunol. 2011; 12:966-974. [PubMed: 21892173]

89. Kinjo Y, et al. Natural killer T cells recognize diacylglycerol antigens from pathogenic bacteria. Nature Immunol. 2006; 7:978-986. [PubMed: 16921381]

90. Kinjo Y, et al. Recognition of bacterial glycosphingolipids by natural killer T cells. Nature. 2005; 434:520-525. This report describes the importance of NKT cells in protective immunity to infection. [PubMed: 15791257]

91. Fischer K, et al. Mycobacterial phosphatidylinositol mannoside is a natural antigen for CD1drestricted T cells. Proc Natl Acad Sci USA. 2004; 101:10685-10690. [PubMed: 15243159]

92. Chang YJ, et al. Influenza infection in suckling mice expands an NKT cell subset that protects against airway hyperreactivity. J Clin Invest. 2011; 121:57-69. [PubMed: 21157038]

93. Wu D, et al. Design of natural killer T cell activators: structure and function of a microbial glycosphingolipid bound to mouse CD1d. Proc Natl Acad Sci USA. 2006; 103:3972-3977. [PubMed: 16537470]

94. Wang J, et al. Lipid binding orientation within CD1d affects recognition of Borrelia burgorferi antigens by NKT cells. Proc Natl Acad Sci USA. 2010; 107:1535-1540. [PubMed: 20080535]

95. Zeissig S, et al. Hepatitis B virus-induced lipid alterations contribute to natural killer T celldependent protective immunity. Nature Med. 2012; 18:1060-1068. This report describes a role for phospholipid- reactive type II NKT cells in promoting immunity to hepatitis B virus. [PubMed: 22706385]

96. Brigl M, et al. Innate and cytokine-driven signals, rather than microbial antigens, dominate in natural killer T cell activation during microbial infection. J Exp Med. 2011; 208:1163-1177. [PubMed: 21555485]

97. Chiu YH, et al. Multiple defects in antigen presentation and T cell development by mice expressing cytoplasmic tail-truncated CD1d. Nature Immunol. 2002; 3:55-60. [PubMed: 11731798]

98. Hogquist KA, et al. T cell receptor antagonist peptides induce positive selection. Cell. 1994; 76:17-27. [PubMed: 8287475]

99. Zhou D, et al. Lysosomal glycosphingolipid recognition by NKT cells. Science. 2004; 306:17861789. [PubMed: 15539565]

100. Speak AO, et al. Implications for invariant natural killer T cell ligands due to the restricted presence of isoglobotrihexosylceramide in mammals. Proc Natl Acad Sci USA. 2007; 104:59715976. [PubMed: 17372214]

101. Porubsky S, et al. Normal development and function of invariant natural killer T cells in mice with isoglobotrihexosylceramide (iGb3) deficiency. Proc Natl Acad Sci USA. 2007; 104:59775982. [PubMed: 17372206] 
102. Christiansen D, et al. Humans lack iGb3 due to the absence of functional iGb3-synthase: implications for NKT cell development and transplantation. PLoS Biol. 2008; 6:e172. [PubMed: 18630988]

103. Porubsky S, et al. Globosides but not isoglobosides can impact the development of invariant NKT cells and their interaction with dendritic cells. J Immunol. 2012; 189:3007-3017. [PubMed: 22875802]

104. Facciotti F, et al. Peroxisome-derived lipids are self antigens that stimulate invariant natural killer T cells in the thymus. Nature Immunol. 2012; 13:474-480. [PubMed: 22426352]

105. Zajonc DM, Ainge GD, Painter GF, Severn WB, Wilson IA. Structural characterization of mycobacterial phosphatidylinositol mannoside binding to mouse CD1d. J Immunol. 2006; 177:4577-4583. [PubMed: 16982895]

106. Zajonc DM, Savage PB, Bendelac A, Wilson IA, Teyton L. Crystal structures of mouse CD1diGb3 complex and its cognate Va14 T cell receptor suggest a model for dual recognition of foreign and self glycolipids. J Mol Biol. 2008; 377:1104-1116. [PubMed: 18295796]

107. Macdonald WA, et al. T cell allorecognition via molecular mimicry. Immunity. 2009; 31:897908. [PubMed: 20064448]

108. Archbold JK, et al. Natural micropolymorphism in human leukocyte antigens provides a basis for genetic control of antigen recognition. J Exp Med. 2009; 206:209-219. [PubMed: 19139173]

109. Tynan FE, et al. A T cell receptor flattens a bulged antigenic peptide presented by a major histocompatibility complex class I molecule. Nature Immunol. 2007; 8:268-276. [PubMed: 17259989]

110. Gumperz JE, et al. Murine CD1d-restricted T cell recognition of cellular lipids. Immunity. 2000; 12:211-221. [PubMed: 10714687]

111. Matulis G, et al. Innate-like control of human iNKT cell autoreactivity via the hypervariable CDR3 $\beta$ loop. PLoS Biol. 2010; 8:e1000402. [PubMed: 20585371]

112. Muindi K, et al. Activation state and intracellular trafficking contribute to the repertoire of endogenous glycosphingolipids presented by CD1d. Proc Natl Acad Sci USA. 2010; 107:30523057. [PubMed: 20133624]

113. Blomqvist M, et al. Multiple tissue-specific isoforms of sulfatide activate CD1d-restricted type II NKT cells. Eur J Immunol. 2009; 39:1726-1735. [PubMed: 19582739]

114. Chang DH, et al. Inflammation associated lysophospholipids as ligands for CD1d restricted T cells in human cancer. Blood. 2008; 112:1308-1316. [PubMed: 18535199]

115. Fox LM, et al. Recognition of lysophospholipids by human natural killer T lymphocytes. PLoS Biol. 2009; 7:e1000228. [PubMed: 19859526]

116. Pei B, et al. Diverse endogenous antigens for mouse NKT cells: self-antigens that are not glycosphingolipids. J Immunol. 2011; 186:1348-1360. [PubMed: 21191069]

117. Berzofsky JA, Terabe M. NKT cells in tumor immunity: opposing subsets define a new immunoregulatory axis. J Immunol. 2008; 180:3627-3635. [PubMed: 18322166]

118. Patel O, et al. Recognition of CD1d-sulfatide mediated by a type II natural killer T cell antigen receptor. Nature Immunol. 2012; 13:857-863. [PubMed: 22820603]

119. Girardi E, et al. Type II natural killer T cells use features of both innate-like and conventional T cells to recognize sulfatide self antigens. Nature Immunol. 2012; 13:851-856. Together with reference 118, this study provided the first description of a type II NKT TCR-antigen-CD1d interaction. [PubMed: 22820602]

120. Monzon-Casanova E, et al. CD1d expression in Paneth cells and rat exocrine pancreas revealed by novel monoclonal antibodies which differentially affect NKT cell activation. PLoS ONE. 2010; 5:e13089. [PubMed: 20927351]

121. Krogsgaard M, et al. Agonist/endogenous peptide-MHC heterodimers drive T cell activation and sensitivity. Nature. 2005; 434:238-243. [PubMed: 15724150]

122. Agea E, et al. Human CD1-restricted T cell recognition of lipids from pollens. J Exp Med. 2005; 202:295-308. [PubMed: 16009719]

123. Umetsu DT, DeKruyff RH. Natural killer T cells are important in the pathogenesis of asthma: the many pathways to asthma. J Allergy Clin Immunol. 2010; 125:975-979. [PubMed: 20338622] 
124. Braun NA, Covarrubias R, Major AS. Natural killer T cells and atherosclerosis: form and function meet pathogenesis. J Innate Immun. 2010; 2:316-324. [PubMed: 20375560]

125. Kunii N, et al. Combination therapy of in vitro-expanded natural killer T cells and agalactosylceramide-pulsed antigen-presenting cells in patients with recurrent head and neck carcinoma. Cancer Sci. 2009; 100:1092-1098. [PubMed: 19302288]

126. Yamasaki K, et al. Induction of NKT cell-specific immune responses in cancer tissues after NKT cell-targeted adoptive immunotherapy. Clin Immunol. 2011; 138:255-265. [PubMed: 21185787]

127. Reantragoon R, et al. Structural insight into MR1-mediated recognition of the mucosal associated invariant T cell receptor. J Exp Med. 2012; 209:761-774. [PubMed: 22412157]

128. Treiner E, et al. Selection of evolutionarily conserved mucosal-associated invariant $\mathrm{T}$ cells by MR1. Nature. 2003; 422:164-169. [PubMed: 12634786]

129. Hooper LV, Littman DR, Macpherson AJ. Interactions between the microbiota and the immune system. Science. 2012; 336:1268-1273. [PubMed: 22674334]

130. López-Sagaseta J, Kung JE, Savage PB, Gumperz J, Adams EJ. The molecular basis for recognition of CD1d/a-galactosylceramide by a human non-Va24 T cell receptor. PLoS Biol. 2012; 10:e1001412. [PubMed: 23109910]

131. Kjer-Nielsen L, et al. MR1 presents microbial vitamin B metabolites to MAIT cells. Nature. Oct $10.201210 .1038 /$ nature 11605 

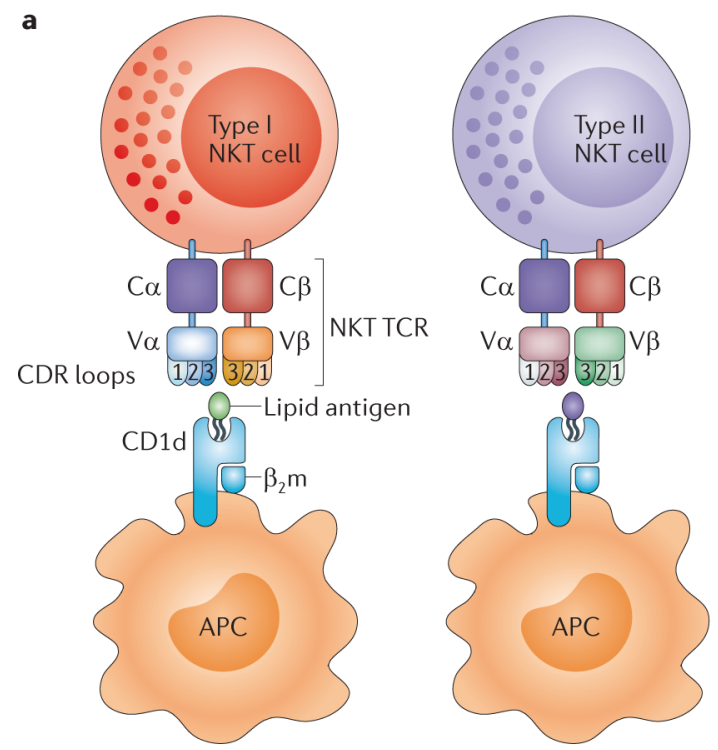

b
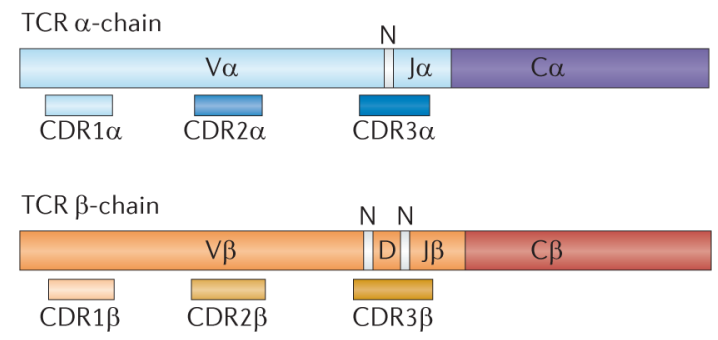

Figure 1. NKT cells

a The figure shows a schematic representation of type I and type II natural killer T (NKT) cells. These two subsets use different variable $(V)$ region gene segments in the $\alpha$ - and $\beta$ chains of their T cell receptors (TCRs), and they recognize different CD1d-restricted antigens. $\mathbf{b} \mid$ The $a \beta$ TCR is composed of two chains, with the $V$ domains containing the complementarity-determining region (CDR) loops. The CDR3 loops are encoded by multiple gene segments and also contain non-templated $(\mathrm{N})$ regions, which add further diversity to the TCR repertoire. The colour coding is the same as that used for the type I NKT TCR in part a. $\beta_{2} \mathrm{~m}, \beta_{2}$-microglobulin; APC, antigen-presenting cell; C, constant; D, diversity; J, joining. 


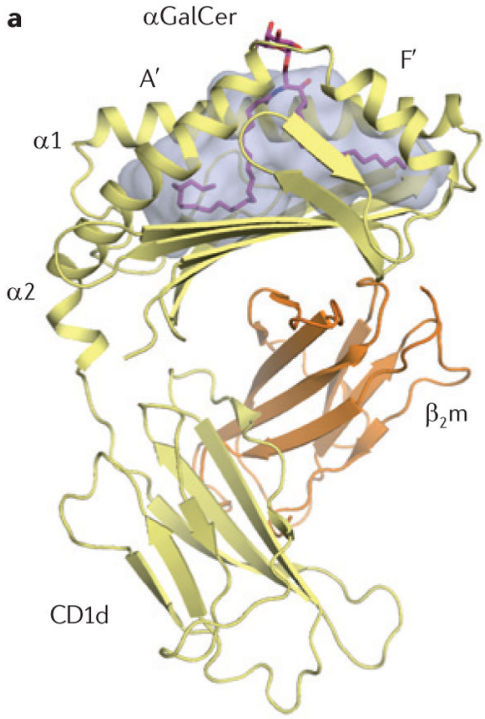

b

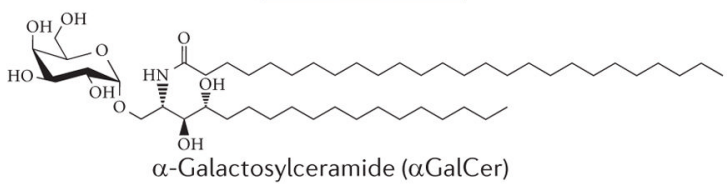

(OCH

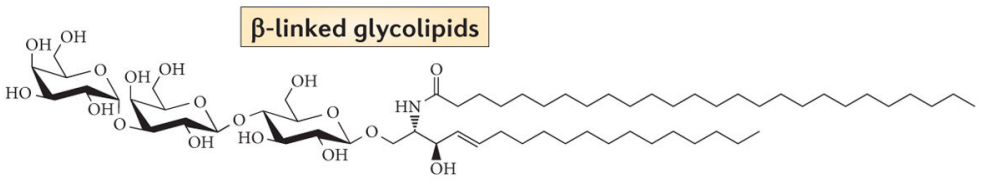

Isoglobotrihexosylceramide (iGb3)

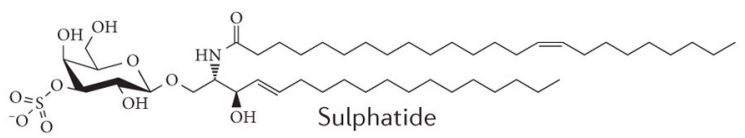

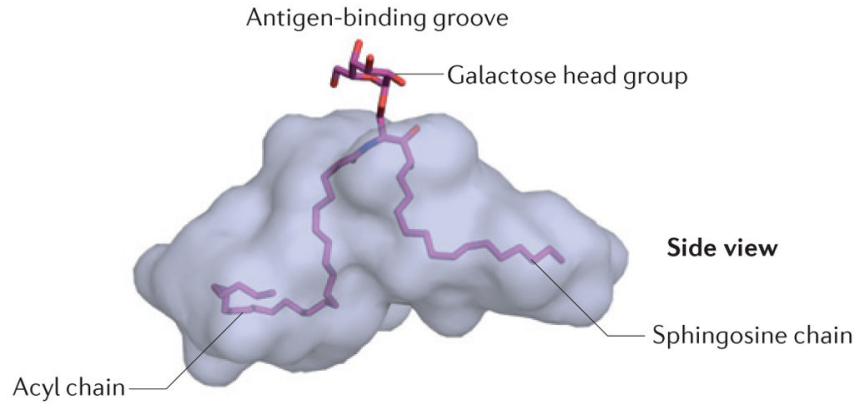

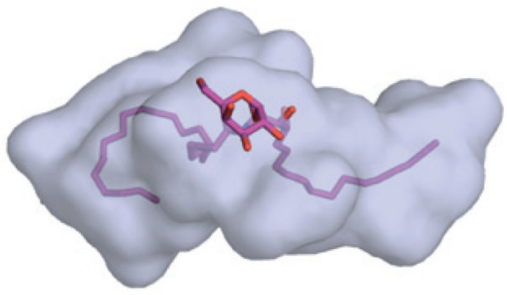

Top view
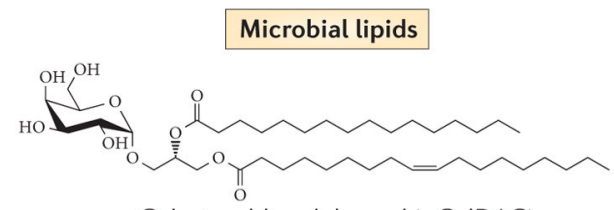

$\alpha$-Galactosyldiacylglycerol ( $\alpha$ GalDAG)

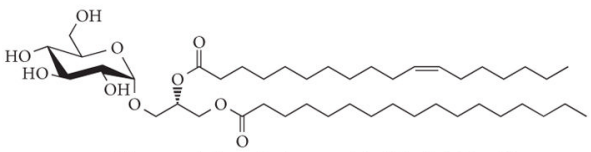

$\alpha$-Glucosyldiacylglycerol ( $\alpha$ GlcDAG-s2)

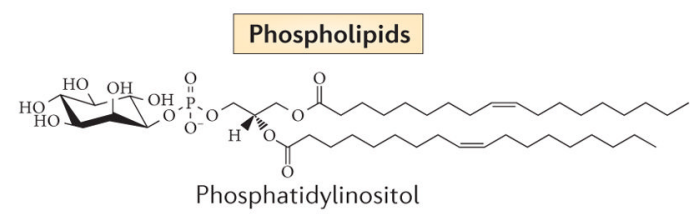

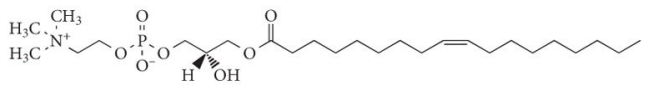

Lysophosphatidylcholine

Figure 2. CD1d-mediated antigen presentation

a | The figure shows the structure of human CD1d bound to a-galactosylceramide (aGalCer) (PDB code 1ZT4). a GalCer is positioned within the CD1d antigen-binding groove, which is characterized by two main pockets: the $\mathrm{A}^{\prime}$-pocket and the $\mathrm{F}^{\prime}$-pocket. The galactose head group is surface exposed, whereas the lipid tails are buried within the cavity. b $\mid$ The figure shows the chemical structures of various lipid antigens that bind to CD1d. These include examples of synthetic lipids (aGalCer and $\mathrm{OCH})$, microbial lipids (agalactosyldiacylglycerol from Borrelia burgdorferi and a-glucosyldiacylcerol from Streptococcus pneumoniae), $\beta$-linked glycolipids (isoglobotrihexosylceramide and sulphatide) and phospholipids (phosphatidylinositol and lysophosphatidylcholine). $\beta_{2} \mathrm{~m}, \beta_{2^{-}}$ microglobulin. 

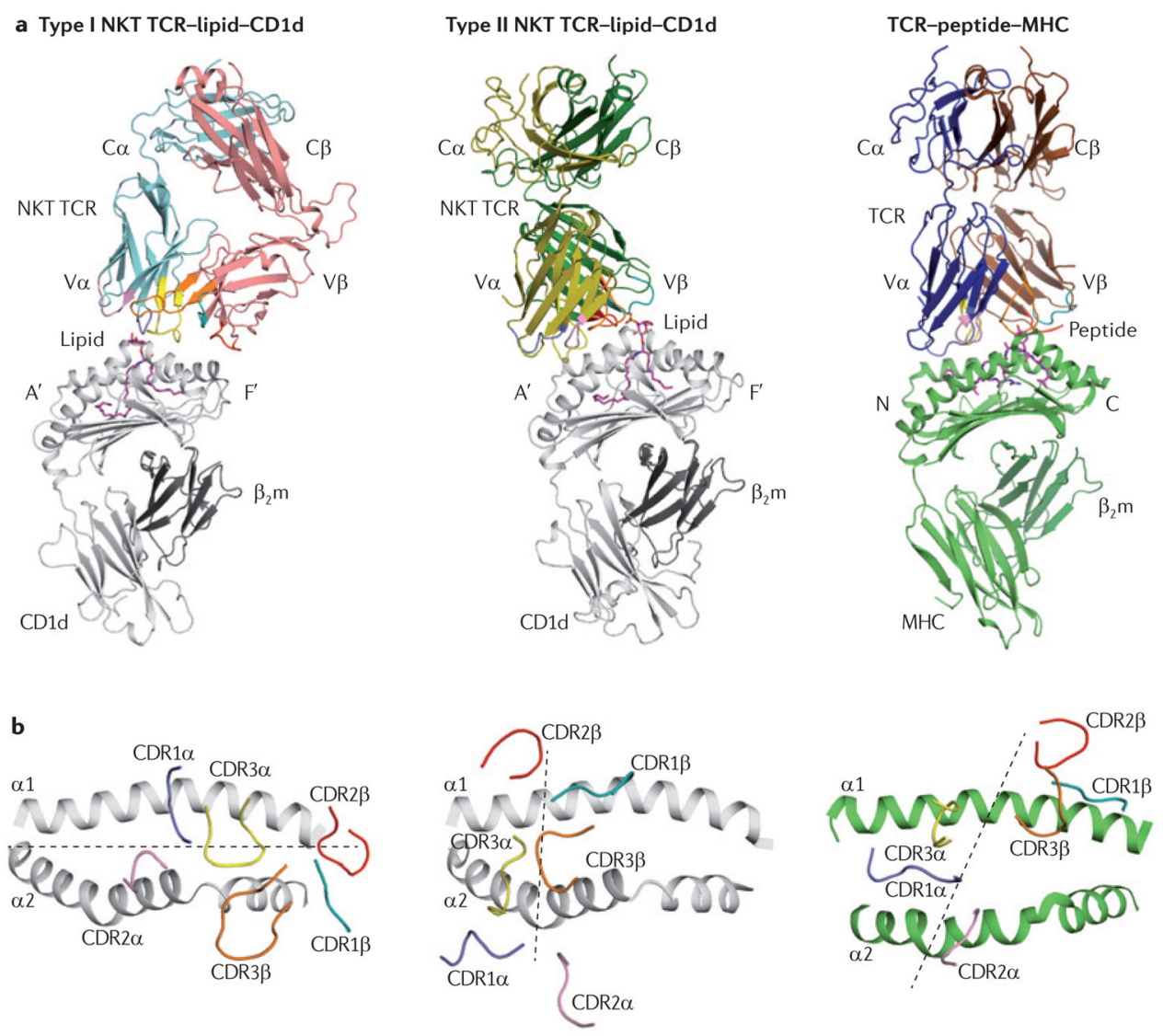

Figure 3. Structural comparison between NKT TCR-lipid-CD1d complexes and the conventional TCR-peptide-MHC complex

a $\mid$ The figure shows the docking mode of the T cell receptor (TCR) in a type I natural killer T (NKT) cell TCR-lipid-CD1d complex (left; PDB code 2PO6), a type II NKT TCR-lipidCD1d complex (middle; PDB code 4EI5) and a TCR-peptide-MHC complex (right; PDB code $3 \mathrm{SJV}$ ). The CD1d antigen-binding pockets are labelled $\mathrm{A}^{\prime}$ and $\mathrm{F}^{\prime}$, and the amino and carboxyl termini of the peptide are labelled $\mathrm{N}$ and $\mathrm{C}$, respectively. $\mathbf{b} \mid$ The figure shows the view looking down into the antigen-binding groove of the three complexes showing the parallel docking mode in the type I NKT-lipid-CD1d complex (left), the orthogonal docking mode in the type II NKT-lipid-CD1d complex (middle) and the diagonal docking mode in the TCR-peptide-MHC complex (right). Dashed lines represent the docking mode. $\beta_{2} \mathrm{~m}, \beta_{2}$-microglobulin. 

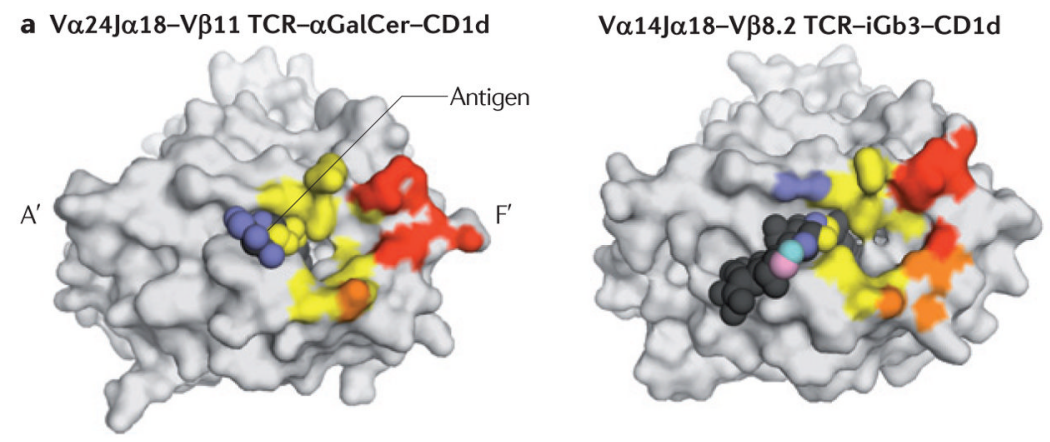

b V $\alpha 10 \mathrm{~J} \alpha 50-\mathrm{V} \beta 8.1 \mathrm{TCR}-\alpha \mathrm{GlcCer-CD} 1 \mathrm{~d}$
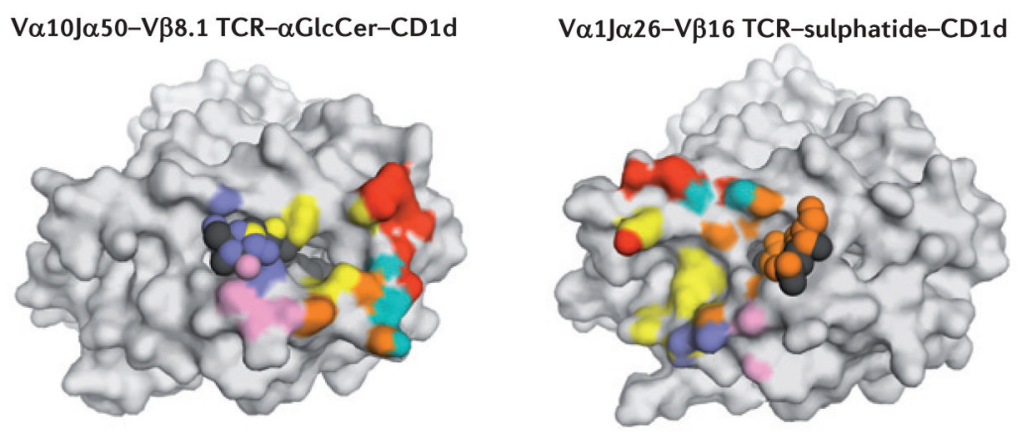

\begin{tabular}{|l|r|}
\hline CDR1 $\alpha$ & CDR1 $\beta$ \\
\hline CDR2 $\alpha$ & CDR2 $\beta$ \\
\hline $\operatorname{CDR} 3 \alpha$ & CDR3 $\beta$ \\
\hline
\end{tabular}

Figure 4. The footprint of contact made by NKT TCRs on the surface of CD1d. a

| The image on the left shows the footprint of the human type I natural killer T (NKT) cell Va24Ja18-V $\beta 11 \mathrm{~T}$ cell receptor (TCR) on the surface of human CD1d, which is presenting an a-linked glycolipid, a-galactosylceramide (aGalCer) (PDB code 2PO6). The image on the right shows the footprint of the mouse type I NKT cell Va14Ja18-V $\beta 8.2$ TCR on the surface of mouse CD1d, which is presenting a $\beta$-linked glycolipid, isoglobotrihexosylceramide (iGb3) (PDB code 3SCM). b On the left is the footprint of the type I NKT cell Va10Ja50-V $\beta 8.1$ TCR on the surface of mouse CD1d, which is presenting aglucosylceramide (aGlcCer) (PDB code 3RUG). On the right is the footprint of the mouse type II NKT cell Va1Ja26-V $\beta 16$ TCR on the surface of mouse CD1d, which is presenting a $\beta$-linked self glycolipid, sulphatide (PDB code 4EI5). 

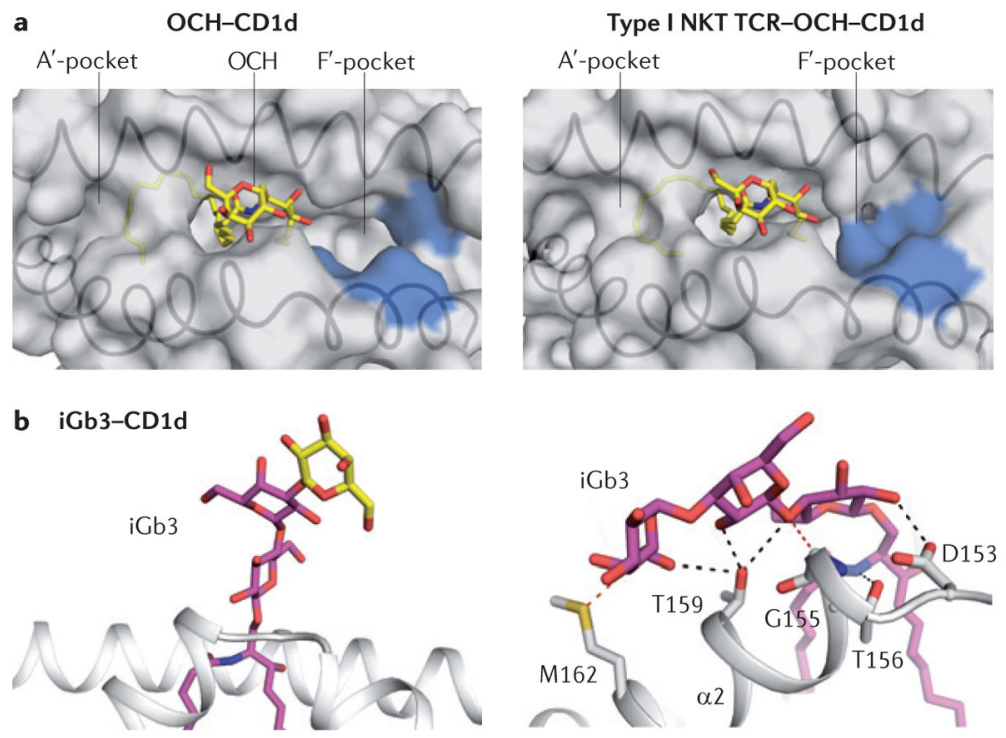

Figure 5. Changes in the conformation of the lipid or CD1d following binding to NKT TCRs a | The image on the left shows a surface representation of the a-galactosylceramide analogue $\mathrm{OCH}$ presented by $\mathrm{CD} 1 \mathrm{~d}$, showing the $\mathrm{A}^{\prime}$ and $\mathrm{F}^{\prime}$ pockets (PDB code $3 \mathrm{G} 08$ ). The image on the right shows the closing of the $\mathrm{F}^{\prime}$-pocket roof in the CD1d-OCH complex following binding to the $\mathrm{T}$ cell receptor (TCR) (PDB code $3 \mathrm{ARB}$ ), which is caused by movement of the side chains of Leu84, Val149 and Leu150 in CD1d (these residues are shown in blue). $\mathbf{b} \mid$ On the left is the structure of the $\beta$-linked glycolipid isoglobotrihexosylceramide (iGb3) presented by CD1d (PDB code 2Q7Y). The terminal sugar for iGb3 is modelled and shown in yellow. The image on the right shows the extensive interactions between the three sugars of the iGb3 head group and the residues of the CD1d a 2-helix within type I natural killer T (NKT) cell TCR-iGb3-CD1d complex (PDB code 3SCM). 

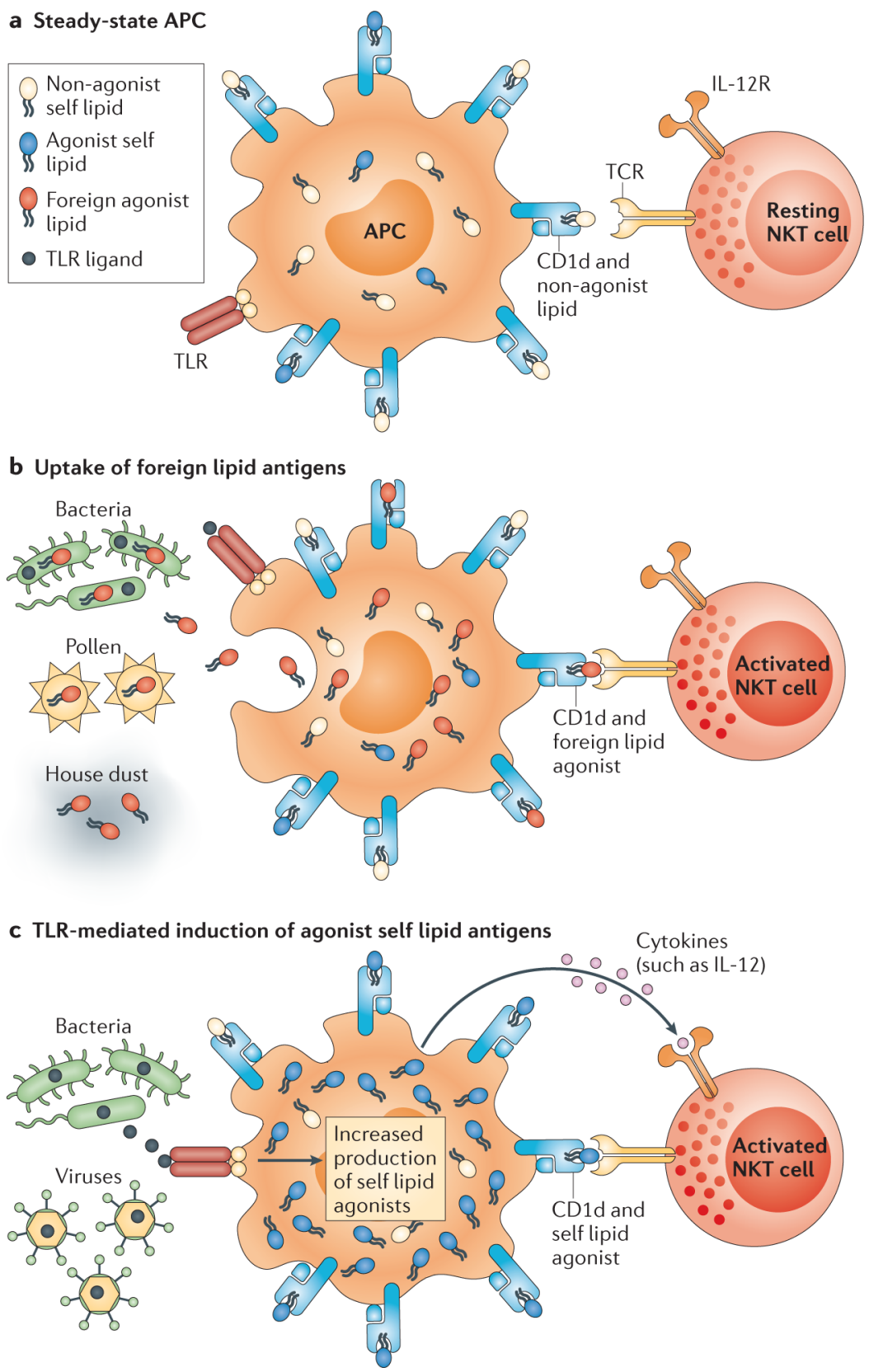

\section{Figure 6. Modes of NKT cell activation}

a In the steady state, antigen-presenting cells (APCs) present non-agonist self lipids on CD1d molecules that do not promote the activation of the natural killer T (NKT) cell T cell receptor (TCR).b $\mid$ APCs can present non-self lipids derived from bacteria or environmental allergens on CD1d molecules. The direct recognition of foreign lipid antigens from these sources can promote NKT cell activation. $\mathbf{c} \mid$ Activation of Toll-like receptors (TLRs) on APCs can induce the production of self lipid antigens (such as $\beta$-galactosylceramide) that can serve as agonists for the NKT TCR. Recognition of these CD1d-presented self lipid agonists, in conjunction with exposure to TLR-induced inflammatory cytokines, leads to NKT cell activation. IL-12, interleukin-12; IL-12R, IL-12 receptor. 


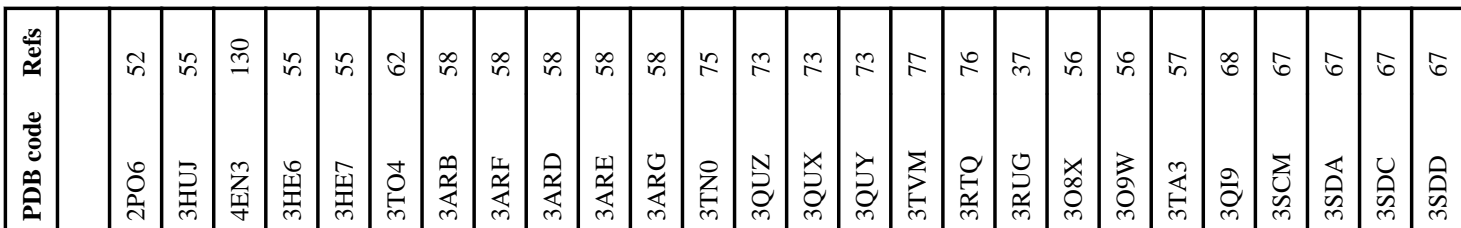

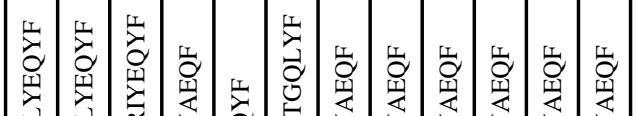

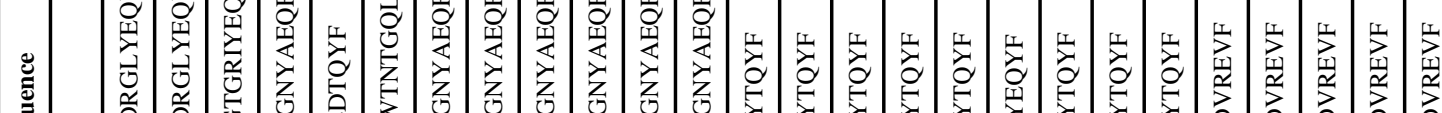

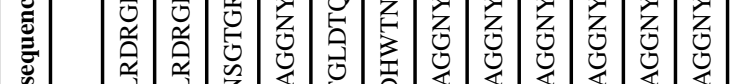

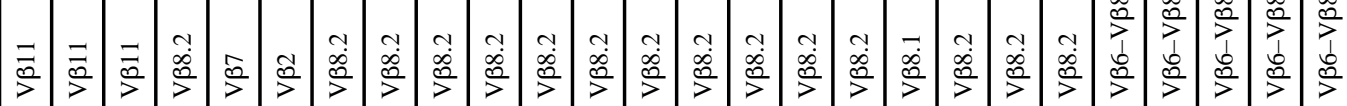

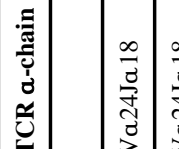

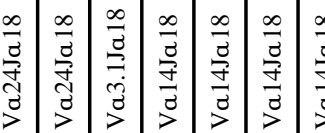

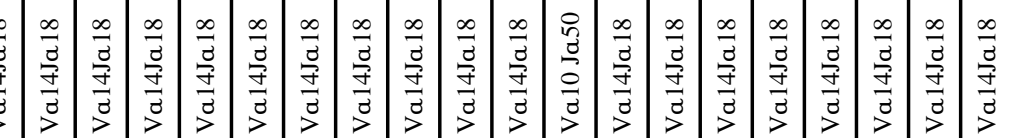

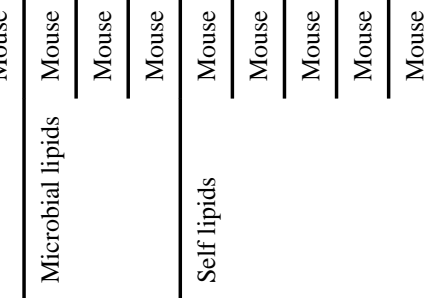


范

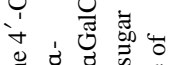

势

3ิ

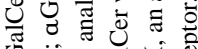

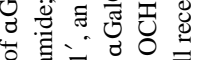

일

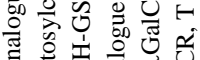

ส

ฮ

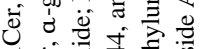

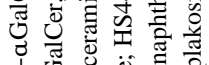

त्र

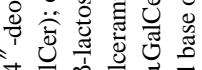

i 응

俅艺论

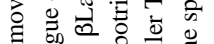

을 웜을

क्ष है है

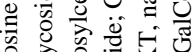

on of 을 光

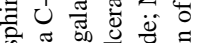

क⿺ 万ह

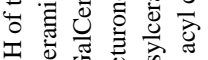

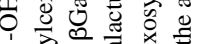

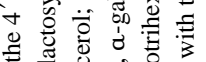

대에

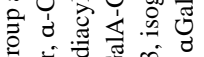

ถั

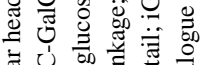

空

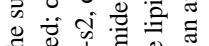

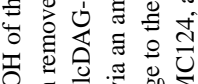

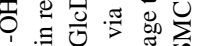

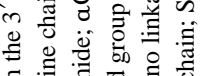

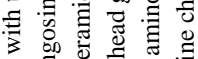

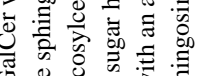

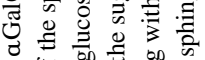

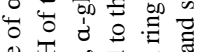

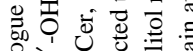

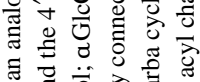

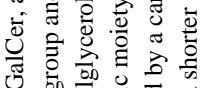

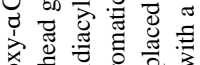

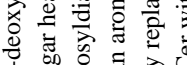

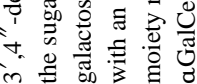

Nat Rev Immunol. Author manuscript; available in PMC 2013 December 01. 